\title{
THE EFFECT OF EXTERNAL PRESSURE ON THE VASCULAR VOLUME OF THE FOREARM AND ITS RELATION TO CAPILLARY BLOOD PRESSURE AND VENOUS PRESSURE
}

\author{
By CHARLES E. MCLENNAN,1 MARGARET T. MCLENNAN, AND \\ EUGENE M. LANDIS \\ (From the Department of Internal Medicine, University of Virginia, Charlottesville)
}

(Received for publication December 29, 1941)

While the direct measurement of capillary blood pressure in man by means of a micro-pipette (1, $2,3)$ is quite accurate, this method has several disadvantages which have prevented wide application to clinical problems. They are $(a)$ the great variability of readings in single capillaries, which makes it practically impossible to obtain a statistically significant number of readings in a given patient at any one time in his illness; $(b)$ the restriction of this method to the capillaries of the skin of the nail fold where the vessels may not be typical of those in muscle or general connective tissue; and $(c)$ the nearness of arteriovenous anastomoses which, by opening and closing, may disturb pressures in the nearby capillaries of the nail fold.

The indirect methods are easily applied to clinical problems but, as pointed out previously (4), lead to widely different estimates of blood pressure in the capillaries or minute vessels as a whole, as might be expected from the subjective and arbitrary nature of the criteria adopted by each investigator to indicate a state of balance between the externally applied pressure and capillary blood pressure. Eichna and Bordley (3) have compared the direct and indirect procedures; they concluded that the usual capsular method, with microscopic observation of the collapse of individual capillaries, was wholly undependable.

Fundamentally, nearly all indirect methods for measuring blood pressure in the minute vessels involve the application of external pressure to diminish the volume of one or more capillaries, using visual evidence such as cessation of flow, modification of flow, or changes in skin color to indicate when the applied pressure is great enough to obliterate or at least flatten, the capillaries under observation. It seems possible, however,

\footnotetext{
1 Commonwealth Fund Fellow, 1940-41.
}

that the average pressure in the minute vessels of human skin and muscle might be estimated plethysmographically by determining the effect of graded external pressure on the collective vascular volume of the forearm. The plethysmograph, by adding together the infinitesimal changes in volume of many individual vessels, might then provide an average and more objective measure of blood pressure in the capillaries, or at least in the minute vessels as a whole.

This paper describes a series of observations designed to determine $(a)$ the effect of graded external pressure on the volume of blood in the human forearm; $(b)$ the relation of these pressure-volume curves to the previously reported direct readings of capillary blood pressure and venous pressure under like conditions; and (c) the effect of known changes of capillary blood pressure on the pressure-volume curves, for the purpose of assessing the validity and usefulness of this procedure as a method of estimating blood pressure in the minute vessels of man during disease.

\section{APPARATUS}

Whereas the usual form of plethysmograph measures changes in arm volume at or very near atmospheric pressure, Landis and Gibbon (5) devised a "pressure plethysmograph" to measure limb volume under external pressures as high as $200 \mathrm{~mm}$. $\mathrm{Hg}$. In previous studies (5) high external pressure was used in order to collapse the blood vessels completely and thus permit accurate estimation of the volume of extravascular fluid. Conversely, in the studies now reported, the pressure applied to the forearm in the plethysmograph ranged from 5 to $120 \mathrm{~mm}$. $\mathrm{Hg}$, while circulation was stopped temporarily, and then restored, to measure the effect of graded external pressure on vascular volume.

The plethysmograph itself required no important modification from that described by Landis and Gibbon (5) and diagrammed on page 110 of that paper, to which the reader is referred for details. The accessory portions of 


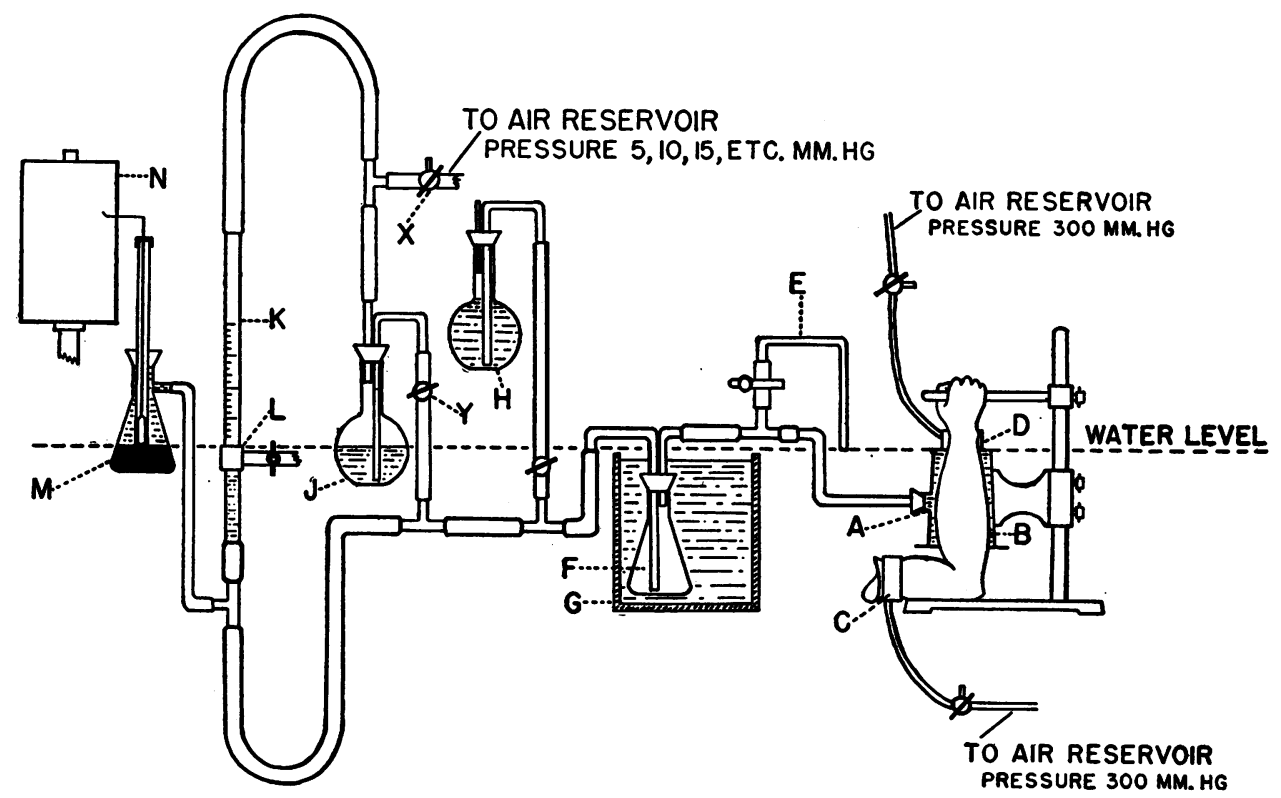

Fig. 1. Diagram of Pressure Plethysmograph and Attached Apparatus

For description see text. For details of pressure plethysmograph see p. 110 of reference 5.

the apparatus required several changes. The large opening into the center of the plethysmograph (Figure 1, A) was closed by a rubber stopper containing a short piece of glass tubing with an inside diameter of $10 \mathrm{~mm}$. This was connected by heavy-walled pressure tubing of $9 \mathrm{~mm}$. bore to a suitable burette (Figure 1, K). The lower end of the burette was cut off so that it could be inserted directly into the larger rubber tubing which, with large T-tubes, was used to facilitate rapid movement of water throughout the system. A water outlet (Figure 1, E) was adjusted to the height of the plethysmograph, to permit accurate equalization of fluid levels within the system at the beginning of each observation. A $1000 \mathrm{ml}$. flask (Figure 1, F) was immersed in a 20-litre water bath, kept at constant temperature (Figure 1, G), and between the burette and plethysmograph so that as water at room temperature was expelled from the burette into the lower portion of the flask, an equal volume of water at the desired temperature passed from the top of the flask into the plethysmograph, thus maintaining the temperature of the plethysmograph and forearm at the desired level. A $1500 \mathrm{ml}$. flask (Figure 1, H), with an airhole in its stopper, was used merely as a reservoir to introduce or withdraw water from the system in preliminary adjustment and at the end of an experiment.

For measuring changes in volume two different burette systems were found necessary. In some experiments, chiefly observations 1,2 and 6 , below, where large or gross changes in volume were measured, a $250 \mathrm{cc}$. dispensing burette was used alone (Figure 1, K; omitting $\mathrm{J}$ and $\mathrm{Y}$ ). This burette, partially filled with water, communicated by its lower end with the water in the interior of the plethysmograph, and by its upper end, through a three-way stopcock (Figure 1, X), with a 40-liter reservoir (not shown), which contained air previously brought to the desired pressure as indicated by a separate mercury manometer (not shown). Through the three-way stopcock (X) pressure could be applied suddenly to the water in the burette and thence to the forearm, while changes in total volume were followed by observing the reading opposite the water meniscus in the burette. To maintain the pressure on the forearm constant, it was of course necessary to move the burette continuously in the holder, $L$, so that the water meniscus remained opposite the line marked "water level" in Figure 1.

In other observations much smaller changes, comprising vascular volume only, had to be measured more accurately. For these, a $50 \mathrm{cc}$. Shellbach burette (Figure 1, $\mathrm{K})$ with graduations of $0.1 \mathrm{cc}$. was used. To supply the bulk of the preliminary physical change in total volume, which accompanied each change of plethysmographic pressure, a $1000 \mathrm{cc}$. flask (Figure 1, J) half filled with water, and a stopcock (Figure 1, Y) were inserted in parallel to the burette. As in the burette, the water in the lower part of the flask communicated with the water in the plethysmograph while the air in the upper part of the flask communicated through the three-way stopcock (X) with the air reservoir. With stopcock $\mathrm{Y}$ open, any pressure applied through stopcock $X$ displaced fluid from the flask while the volume of water in the burette, except for transient fluctuation, remained almost constant. As the gross shift of fluid ceased, stopcock $Y$ was closed and thereafter smaller changes in volume were followed more accurately by observing the movement of water in the small burette. Whichever burette was used, a mercury manometer (Figure 1, M). recorded on a kymo- 
graph (Figure 1, N) the level and constancy of the pressure exerted by the plethysmograph on the forearm.

Two pneumatic cuffs (Figure 1, C and D), $44 \mathrm{~cm}$. long and $5.5 \mathrm{~cm}$. wide, were available for occluding circulation just below the axilla and at the wrist, respectively. These were connected to another 40-liter reservoir (not shown) containing air under a pressure of $300 \mathrm{~mm}$. $\mathrm{Hg}$. The wrist cuff was kept inflated throughout each observation to exclude possible errors arising from the return of blood from the hand to the veins of the forearm within the plethysmograph.

The temperature of the forearm and surrounding water was controlled by pumping fluid from a water bath (Figure 1, G) through the double-walled jacket of the plethysmograph. A bimetallic thermoregulator kept the water in the bath constantly at the desired temperature, which in all the following observations was $34^{\circ} \mathrm{C}$.

\section{GENERAL METHODS}

The effect of graded external pressure on vascular volume was measured in several ways. Since the initial preparations for all methods were similar they will be described first. An illustrative protocol is given at the end of the paper.

The plethysmograph-burette system, having been brought to a temperature of $34^{\circ} \mathrm{C}$., was prepared by removing all air bubbles, leaving enough water in the system to keep the burette and flasks suitably filled and the thin rubber sleeve collapsed against the inner wall of the plethysmograph. The redundant portions of the collapsed plethysmograph sleeve were arranged in folds equally at the two ends of the plethysmograph and the washers, aluminum plates, and brass rings were assembled loosely in their proper positions.

With the subject supine, a coating of talc was applied to the skin of the forearm so that the rubber sleeve (Figure 1, B) might move smoothly over the skin. The hand was slipped into the plethysmograph, which was then lowered over the forearm until its midpoint lay at the level of the manubrium sterni. In its final position the upper arm was abducted about $45^{\circ}$; the elbow was flexed at right angles to the upper arm so that the forearm was perpendicular to the table. The elbow and distal quarter of the posterior surface of the arm rested on the base of the iron standard (see Figure 1) to prevent the conical forearm from being pushed out of the plethysmograph when pressure was applied. The fingers were flexed lightly over a horizontal rod containing a wood hand grip and covered loosely with adhesive tape. The inner light rubber portions of the washers, along with the redundant sleeve ends, were invaginated along the forearm, and the aluminum diaphragms were clamped tightly in position with their edges near, but not actually touching, the skin. Special care was necessary in this adjustment to prevent subsequent tightness of the diaphragms from producing venous congestion.

The overflow tube (Figure 1, E) was adjusted so that its orifice was level with the upper (wrist) diaphragm of the plethysmograph. The water in flask J, the marker for the burette (Figure 1, L), and the mercury manometer (Figure 1, M) were all brought accurately to this same level.

One of the narrow pneumatic cuffs was wrapped around the wrist immediately above the upper aluminum diaphragms, and the second cuff was placed as high as possible on the upper arm.

Stopcock $\mathrm{X}$ was opened to room air to permit water to enter the burette and reservoir $\mathrm{J}$ was isolated from the system temporarily to avoid changing its water level during the filling period. The burette-plethysmograph system was filled from flask $\mathrm{H}$ with enough water to produce a slight positive pressure in the plethysmograph and thus to force the rubber sleeve closely against the forearm. The pressure then was reduced to atmospheric level by opening the overflow tube $\mathrm{E}$ and simultaneously stopcock $Y$ was opened to allow water in the burette reservoir to assume precisely the level of the water in the burette and plethysmograph.

After closing the overflow tube $\mathrm{E}$, the pressure in the plethysmograph was raised to $100 \mathrm{~mm}$. $\mathrm{Hg}$ and lowered again to zero in a few seconds; this was repeated three times in quick succession to settle the rubber sleeve in position. Thereafter the water meniscus in the burette was kept opposite the point of reference (L) by moving the burette either up or down in its holder. Since the volume and pressure of water per se remained the same throughout each observation, changes in the volume of the forearm could be determined directly from the burette readings, while pressure in the plethysmograph was indicated simultaneously by the mercury manometer (M). From this point on, methods varied considerably and will be presented in the form of descriptions or specific protocols accompanying the corresponding observations.

\section{OBSERVATIONS}

\section{The pressure-volume curve of the burette and plethysmograph system alone}

The application of pressure to the interior of a system which is not absolutely rigid, because of rubber tubing and slight bulging of the diaphragms, will mechanically increase the volume of the entire system. To determine the magnitude of these changes, and the time required for a purely physical equilibrium to develop at each pressure, a glass cylinder (to represent the forearm) was placed in the plethysmograph and pressure was raised stepwise from 0 to $120 \mathrm{~mm}$. $\mathrm{Hg}$. Curve $\mathrm{A}$ in Figure 2 illustrates the magnitude of the observed changes in volume. At a pressure of $10 \mathrm{~mm} . \mathrm{Hg}$ the volume of the system increased by approximately $13 \mathrm{cc}$; at $20 \mathrm{~mm}$. $\mathrm{Hg}$ by $20 \mathrm{cc}$. ; and at $120 \mathrm{~mm}$. $\mathrm{Hg}$ by $39 \mathrm{cc}$. For any one setting of the plethysmograph and its diaphragms 


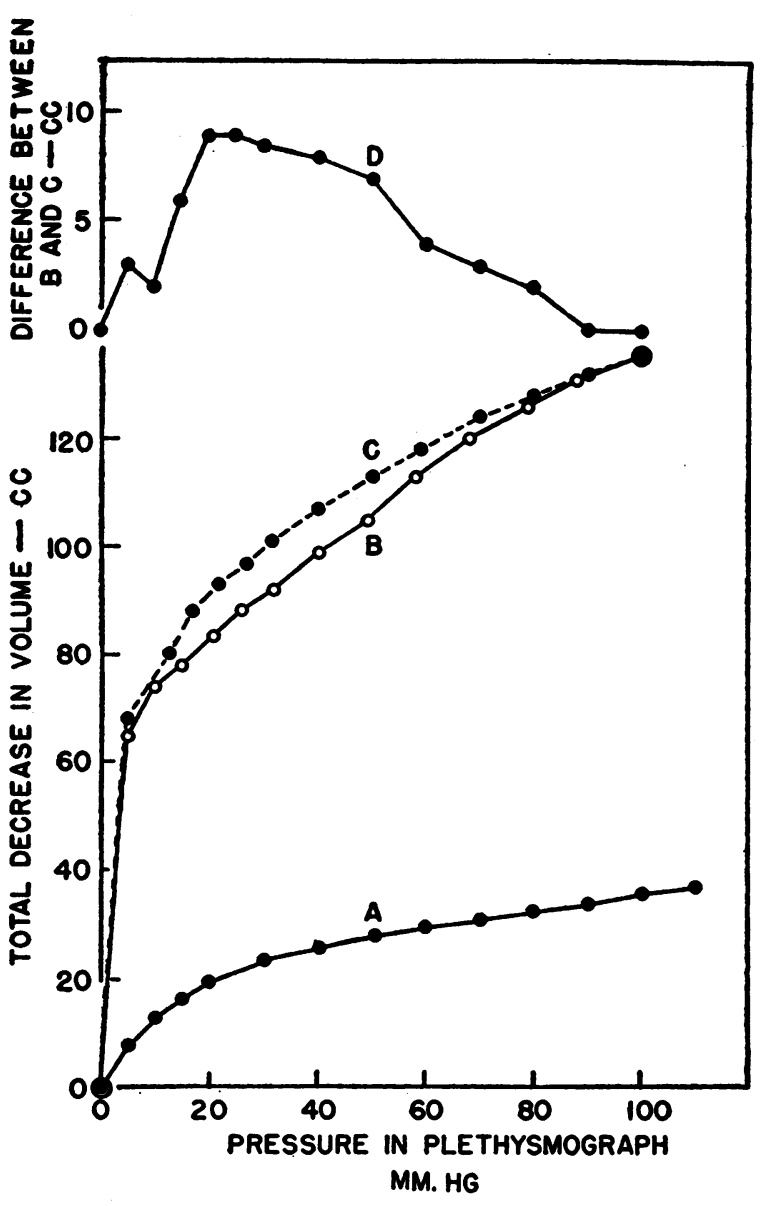

Fig. 2. Showing Effect of Pressure on Volume

Of burette-plethysmograph system containing glass cylinder (curve A); of forearm with circulation free (curve B); and of forearm with circulation occluded at the axilla (curve $C$ ). Curve $D$ represents the difference between curve $\mathrm{C}$ and $\mathrm{B}$, or "dynamic vascular volume."

the shape and position of rapidly repeated curves were extremely constant, indicating uniform and dependable apposition of the thin rubber sleeve against the cylinder within the plethysmograph, as well as uniform distortion of the diaphragms. After each change of pressure it required less than 3 seconds to reach physical equilibrium.

When high pressures were applied for several hours, slight but definite irreversible stretching of the system was observed. Thus at intervals of 30 minutes, in one observation a pressure of $120 \mathrm{~mm}$. $\mathrm{Hg}$ increased the volume of the system by 37.0, $37.0,37.0,37.5$ and $39.5 \mathrm{cc}$. At lower pressures, between 5 and $40 \mathrm{~mm}$. $\mathrm{Hg}$, this effect was also present but considerably less, amounting to not more than $1.0 \mathrm{cc}$. over a 3-hour period.

These observations made it obvious that until an absolutely indistensible plethysmograph system can be devised, studies of pressure-volume relationship must be arranged (a) to exclude, or at least to cancel out, errors arising from expansion of the plethysmograph and its tubing; and, $(b)$ to eliminate the slight but definite distension accompanying prolonged internal pressure by making each separate observation as brief as possible.

2. Gross pressure-volume curves of the forearm

(a) with circulation intact and (b) with circulation occluded

When the forearm was placed in the plethysmograph the position and shape of the gross pressure-volume curve depended upon the presence or absence of circulation as shown in Figure 2 , curves $B$ and $C$ respectively. In this observation the forearm of a normal male subject was placed in the plethysmograph as described under "General Methods," using the 250 cc. burette. The temperature of the forearm and plethysmograph was $34^{\circ} \mathrm{C}$., while room temperature was $29^{\circ} \mathrm{C}$. One narrow pneumatic cuff was wrapped around the wrist just distal to the plethysmograph and another as high as possible on the upper arm just distal to the axilla.

At zero time the wrist cuff was inflated to 300 $\mathrm{mm}$. $\mathrm{Hg}$ to exclude the flow of blood to and from the hand. At the end of one minute a burette reading was recorded and from it, as a zero point, succeeding changes in volume were computed. Pressure was first raised to $5 \mathrm{~mm}$. $\mathrm{Hg}$ and a relatively large volume of water moved rapidly from the burette into the plethysmograph. Since equilibrium with the forearm was reached more slowly than with the glass cylinder, one minute was allowed to elapse before reading the gross change in volume corresponding to an external pressure of $5 \mathrm{~mm}$. This volume having been recorded as $65 \mathrm{cc}$., pressure was raised to $10 \mathrm{~mm}$. $\mathrm{Hg}$, at which pressure the volume $74 \mathrm{cc}$. was reached after one minute, and so on by steps until a pressure of $100 \mathrm{~mm}$. $\mathrm{Hg}$ was attained as shown in the completed curve B of Figure 2. The pressure within the plethysmograph was then reduced to zero and the wrist cuff was deflated. 
Since the observation required 12 minutes, a rest period of like duration was allowed so that reactive hyperemia might subside completely. The subject remained as quiet as possible to prevent any shift in the relative position of the forearm and plethysmograph. At the end of the rest period, with a total elapsed time of 24 minutes, the wrist cuff and also the cuff on the upper arm were inflated to $300 \mathrm{~mm}$. $\mathrm{Hg}$, thus occluding circulation to and from the forearm, except for such small amounts of blood as might pass through anastomotic connections within bone.

A zero reading at zero pressure was again recorded, differing from the first by 2 cc. which indicated a slight but definite shift in the position of the forearm relative to the plethysmograph. From this new zero, curve $C$ of Figure 2 was determined in the manner already described and represented therefore the gross pressure-volume curve of the forearm with circulation occluded.

This latter curve $C$ includes the instrumental changes in volume shown in curve A plus additional mechanical, or non-vascular changes in volume due to the shape and consistency of the forearm. Owing to its conical shape, the forearm tends to move outward from the larger end of the plethysmograph as pressure is raised. This movement is largely, but not completely, prevented by the heavy iron base against which the soft tissues of the elbow rest. Moreover, the plastic tissues of the forearm are to some extent pushed through the openings of the diaphragms as pressure increases.

Curve $B$ includes these mechanical effects plus the distortion produced by active circulation. When blood flow is present and when intravascular pressure is being maintained the forearm resists certain external pressures, notably from 20 to $35 \mathrm{~mm}$. $\mathrm{Hg}$, more than others. This causes curve $B$ to deviate from curve $C$ slightly at low pressures, maximally at pressures between 20 and $35 \mathrm{~mm} . \mathrm{Hg}$ and again less at pressures of $40 \mathrm{~mm}$. $\mathrm{Hg}$ or more. Subtracting curve B from curve $C$ produces curve $D$ (Figure 2 ) which represents the effect of the vis a tergo of blood flow (and intravascular pressure) upon the gross pressure-volume curve, or the effect of external pressure upon "dynamic vascular volume" of the forearm, using that term because the conditions under which the original curves $\mathrm{B}$ and $\mathrm{C}$ were determined differ chiefly in that arterial inflow was present in one instance (B) and occluded in the other (C). The relation between "dynamic vascular volume" and total vascular volume will be discussed in greater detail below. It is sufficient here to point out that "dynamic vascular volume" was greatest when external pressure was between 20 and $35 \mathrm{~mm} . \mathrm{Hg}$, and became less when external pressure was above or below this range. This relationship held qualitatively when the two curves were determined in reverse order and also when pressure was started at $100 \mathrm{~mm}$. $\mathrm{Hg}$ with stepwise reduction to zero. From the quantitative standpoint, however, the results shown in Figure 2 are distinctly better than average. Numerous trials indicated that this method was not adequate for accurate quantitative studies. Slight movement of the arm during the half hour or more required for a complete determination distorted the relation between the two curves and required transpositions which made the results less objective and accurate. The large total volumes involved made it necessary to use a $250 \mathrm{cc}$. burette with calibrations of $1 \mathrm{cc}$. whereas the "dynamic vascular volumes" being measured ranged from 3 to $20 \mathrm{cc}$. For these reasons the method was modified to measure "dynamic vascular volume" only, excluding changes in volume due to mechanical effects. The above observations have been included merely to indicate by the simplest possible method that graded external pressure produces disproportionate changes in the vascular volume of the forearm, and that the summit of this curve is associated with external pressures having an order of magnitude similar to that of capillary blood pressure.

\section{Measurement of "dynamic vascular volume" alone at $34^{\circ} \mathrm{C}$.}

Three methods were used, all of which excluded from measurement the preliminary mechanical changes of volume due to the effects of pressure on the burette-plethysmograph system and on the non-vascular portions of the forearm. The $\mathbf{5 0}$ cc. burette, calibrated to $0.1 \mathrm{cc}$., and the reservoir were inserted in place of the $250 \mathrm{cc}$. burette.

Methods I and II. In Method I external pressures ranging from 0 to $70 \mathrm{~mm}$. $\mathrm{Hg}$ were applied to the surface 
of the forearm. After the circulation had adjusted itself to this pressure, the corresponding "dynamic vascular volume" was measured by determining the decrease in forearm volume produced by total arrest of blood flow and consequent collapse of the blood vessels deprived of the vis a tergo of arterial pressure. In Method II, which always followed immediately after Method I, the final volume reading of the latter was used as a base-line to determine increase in forearm volume produced by filling of blood vessels when blood flow was again restored, external pressure being continued. These methods reduced the time for each observation to 5 minutes or less, and made it possible to use a smaller and more accurate burette.

Protocol 1 illustrates a typical experiment by showing the detailed results of two determinations at 0 and 10 $\mathrm{mm}$. $\mathrm{Hg}$, followed by a tabular summary of results obtained with pressures of 0 to $60 \mathrm{~mm}$. $\mathrm{Hg}$. To begin a determination, pressure in the air reservoir was adjusted to the desired level, e.g. 0, 10, 15, etc. mm. Hg. At 0:00 time the air reservoir was connected, through stopcock $\mathrm{X}$ (Figure 1), with the burette and burette reservoir (Figure $1, \mathrm{~K}$ and $\mathrm{J}$ ); simultaneously the pneumatic cuff at the wrist was inflated to $300 \mathrm{~mm}$. $\mathrm{Hg}$ to prevent returning blood of the hand from modifying the volume of the forearm. When pressures above zero were applied, a large volume of fluid left the reservoir immediately, owing to the mechanical effects already described. The capacity of the reservoir flask $(\mathrm{J})$, connected in parallel to the burette, was so great that despite this considerable movement of fluid, the level of the water in the burette remained very close to that of the stationary marker (L). After 10 seconds, or at time $0: 10$, the reservoir flask $(\mathrm{J})$ was isolated by closing stopcock $(\mathrm{Y})$; thereafter all further volume changes were registered only in the burette.

The water level in the burette became relatively constant about one and one-half minutes after external pressure was first applied and at time 2:00 a burette reading was made (Protocol .1, column 3). Immediately after this, at time $2: 01$, the circulation to the whole extremity was arrested by inflating the cuff near the axilla (C, Figure 1) to $300 \mathrm{~mm}$. $\mathrm{Hg}$.

Water again passed rapidly from the burette into the plethysmograph as the volume of the forearm diminished, owing to collapse of the blood vessels now deprived of the vis a tergo of arterial inflow. Once more, after 30 seconds, volume changed more slowly, amounting finally to between 0.1 and $0.3 \mathrm{cc}$. per 30 seconds. After circulation had been arrested for 2 minutes, a second burette reading was made at time 4:00 (Protocol 1, column 4); and immediately thereafter, at time $4: 01$, the circulation was restored to the arm and forearm by deflating cuff $\mathrm{C}$, external pressure still being continued. The volume of the forearm then increased rapidly as the vessels once more filled with blood, and the water in the burette rose within 10 to 15 seconds to reach a peak level, which was also recorded (time $4: 10$ to $4: 15$, and column 5, Protocol 1). When pressure in the plethysmograph was raised to
$50 \mathrm{~mm} . \mathrm{Hg}$ or more, blood penetrated the forearm segment more slowly than at lower pressures and 45 seconds or more might elapse before this maximum volume was reached. For this reason, pressures in the plethysmograph and wrist cuff were always continued one minute after release of the circulation, so that a final burette reading at time 5:00 (column 6, Protocol 1) would indicate that the change in volume due to reactive hyperemia had definitely passed through its maximum.

The subject could himself detect the changes which external pressure exerted on the rate of vascular filling. At pressures of 0 to $30 \mathrm{~mm}$. $\mathrm{Hg}$, vigorous pulsations could be felt penetrating throughout the forearm almost at once, while at 35 to $50 \mathrm{~mm}$. $\mathrm{Hg}$, pulsation was felt first in the proximal part of the forearm, and then by slow penetration in the distal part of the forearm. At pressures above $50 \mathrm{~mm}$. $\mathrm{Hg}$, pulsation was felt clearly only near the lower diaphragm of the plethysmograph, because high external pressure prevented blood from entering the arterioles and capillaries throughout the compressed segment.

The final reading having been made at time 5:00, the cuff at the wrist was deflated, the burette reservoir was again placed in communication with the burette-plethysmograph system, and the pressure in the entire apparatus was restored to atmospheric level. After a rest interval of 4 minutes, the entire procedure was repeated at the next higher pressure. This sequence was continued, as shown in the table at the end of Protocol 1, until a pressure was reached at which stoppage and restitution of blood flow produced little or no change in the volume of the forearm. It was found advisable to use pressure increments of $5 \mathrm{~mm}$. $\mathrm{Hg}$ until a definite peak in the volume change was reached, but beyond this point, 10 $\mathrm{mm}$. increments were sufficient to complete the observation.

From these data, as illustrated in Protocol 1, were calculated two series of values relating vascular volume to external pressure. Subtracting the figures in column 3 from those in column 4 indicated for each pressure the reduction in vascular volume associated with collapse of vessels during obstruction of blood flow (column 7, Protocol 1). Subtracting figures in column 5 from those in column 4 indicated the increase in the volume of the forearm produced when restored blood flow and intravascular pressure once more expanded the previously compressed vascular bed against external pressure (column 8, Protocol 1). That portion of the procedure concerned with vascular compression will be referred to as Method I, and the subsequent portion dealing with vascular filling with henceforth be referred to as Method II.

Method III. This procedure measured only increase in volume produced by vascular filling when blood flow was resumed after brief occlusion. To reduce the time required for a single determination, together with its rest period, from 9 to 6 minutes, the vessels were emptied more rapidly, but, as the results will show, also less completely under certain extreme conditions.

The apparatus and arm were arranged exactly as in 
Method I. At 0:00 time the wrist cuff was inflated to $300 \mathrm{~mm} . \mathrm{Hg}$; the pressure in the plethysmograph-burette system was elevated to the desired pressure as before, but in addition, the brachial vessels were simultaneously occluded by inflating the cuff on the upper arm to 300 $\mathrm{mm} . \mathrm{Hg}$. The volume of the forearm diminished rapidly and again the rate of change became very slow at the end of 2 minutes. At time 2:00 a burette reading was recorded and the arm cuff was deflated at time 2:00 to release circulation. As in Method II, two final readings were then made, viz., the peak volume reached during reactive hyperemia (time 2:10 to 2:15) and the final volume at the end of one minute (time $3: 00$ ). The wrist cuff was then deflated and pressure in the plethysmograph was reduced to atmospheric level. A rest period of 3 minutes preceded the next determination.

Subtracting the reading taken when the vessels were collapsed at time 2:00 from those taken at the height of hyperemia indicated, for each external pressure, the increase in the volume of the forearm produced when the previously collapsed blood vessels were again distended by the vis a tergo of arterial pressure acting against the pressure imposed upon the surface of the forearm. The values agreed quite closely with those obtained by Method II under normal conditions but deviations were noted under certain abnormal conditions.

Computation of forearm volume. The volume of the segment of forearm enclosed by the plethysmograph was computed according to the methods described previously (6). Dividing the observed changes in forearm volume by the total volume of the segment, reduced the recorded changes in volume to cc. per $100 \mathrm{cc}$. of forearm tissue and permitted comparing vascular volumes in forearms of different sizes.

Figure 3 illustrates the effect of external pressure on "dynamic vascular volume" of the forearm. The upper half shows, for 4 .subjects, the increase in volume produced by filling of the blood vessels after prior collapse (Method III), while the lower half shows the diminution in forearm volume produced by emptying of the blood vessels when circulation was stopped (Method I). As might be expected, the vascular volumes measured during reactive hyperemia, by Methods II and III, were quite similar and always slightly greater than those measured during resting conditions, by Method I. In both groups vascular volume was greatest when external pressure was between 15 and $35 \mathrm{~mm}$. $\mathrm{Hg}$. Though similar in this respect, some curves exhibited a very definite peak, while the highest readings of others took the form of a double peak or even

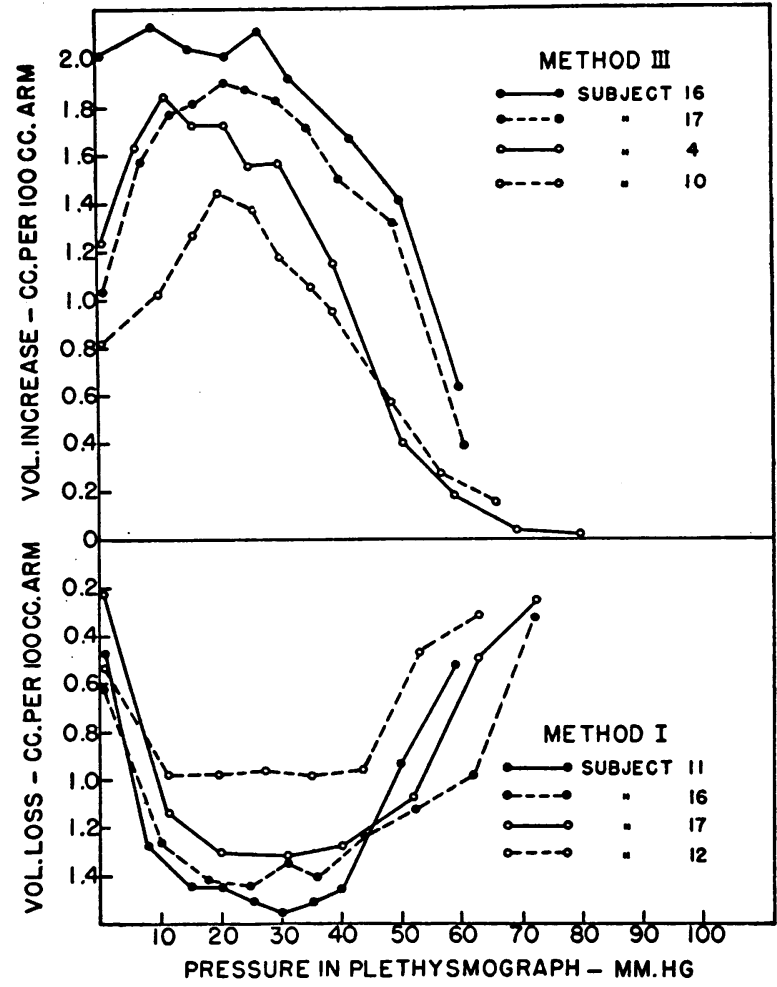

Fig. 3. Showing Pressure-Volume Curves for 4 Subjects

By Method I (emptying of vessels when circulation is stopped) and Method III (filling of vessels when circulation is resumed).

a plateau in which it was impossible by simple inspection to determine any one external pressure at which the change in volume was greatest.

When the same subjects were tested repeatedly the general relationship between external pressure and volume change remained very constant when the curve was viewed as a whole. However, minor differences in configuration indicated that, owing to experimental errors, determination of a single pressure which uniformly produced maximal change in vascular volume could not be accomplished accurately by simple inspection.

It was found that subjective interpretation could be avoided entirely and that consistent values appeared in the same or different individuals if the upper quarter of each curve was made the basis for computation. Therefore, as shown in Figure 4, a transverse line was drawn across the curve at a level one-quarter of the distance from the greatest volume observed to the base-line. 
The two points at which this line crossed the pressure-volume curve indicated the limits of external pressure between which the upper quarter or peak segment of the curve was situated. When a perpendicular was erected from the midpoint of this horizontal line, it divided the area of the summit approximately in half. The external pressure opposite which this perpendicular falls will be referred to in the remainder of this paper as $P_{\text {mvc }}$, or "that external pressure at which the vis a tergo of the circulation is able to keep open the greatest or maximal collective vascular volume." Comparisons of this $P_{m v c}$ with actual peaks or with plateau zones of individual or average curves indicated that this method, in addition to being entirely objective, had less error than inspection, measurement of slopes, and other types of analysis.

Figure 4 shows, in addition, the composite pressure-volume curves and composite $P_{m v c}$ determined from the data for 20 normal subjects obtained by Methods I, II and III when the temperature

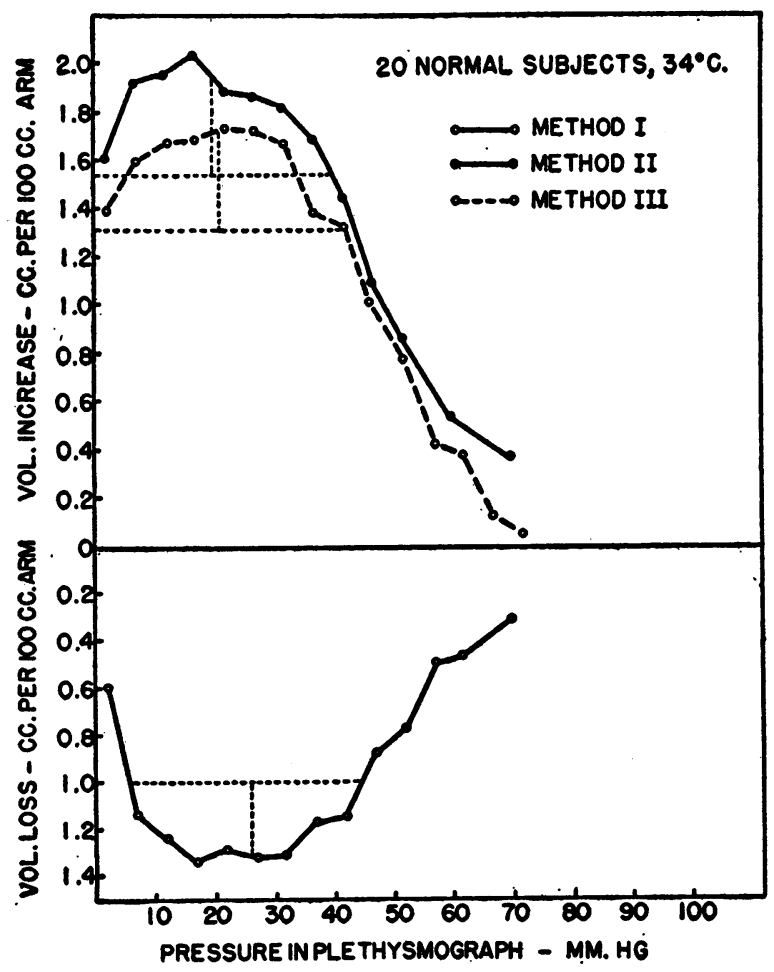

Fig. 4. Showing Average Pressure-Volume Curves FOR MEthods I, II AND III, IN 20 SUBJects

Also illustrates manner of computing $P_{m v o}$. in the plethysmograph was $34^{\circ} \mathrm{C}$. Table I gives the ages, blood pressures, individual values of $P_{m v o}$ and maximal volume changes observed in these same subjects. The values for Method III were obtained on different days from those for Methods I and II, and in some cases several weeks later. The average values of $P_{\text {moc }}$ were 26.9 , 20.7, and $21.3 \mathrm{~mm}$. $\mathrm{Hg}$ by Methods I, II, and III, respectively, while the corresponding average maximal volume changes were $1.38,2.03$ and $1.82 \mathrm{cc}$. per $100 \mathrm{cc}$. of forearm. The range of individual values for $P_{m v c}$ was greater by Methods I and II than by Method III, the respective standard deviations being $3.79,3.38$ and 2.48 . The differences between the mean values for $P_{m v c}$ of Methods I and III and between those of Methods I and II are statistically significant, but the difference between the means of Methods II and III, both related to vascular filling, are insignificant. Corrections for smallness of the samples were made in these computations. The explanation of the minor differences observed will be discussed below. Despite slight differences, however, the pressurevolume curves obtained by 3 different techniques indicated that external pressures exceeding 20 to $35 \mathrm{~mm}$. $\mathrm{Hg}$ reduced "dynamic vascular volume" significantly and that the external pressure corresponding to the summit of the pressure-volume curves, or $P_{m v c}$, had roughly the same order of magnitude as capillary blood pressure measured directly by micro-injection. To test the effect of changing the pressure in the minute vessels, capillary pressure was elevated by known grades of venous congestion, and "dynamic vascular volume" and $P_{m v c}$ were determined under these conditions.

\section{Effects of venous congestion on the pressure- volume curve and $P_{m v c}$}

Venous pressure in the forearm was elevated continuously to the desired level by inflating a large pneumatic cuff, $50 \mathrm{~cm}$. long and $12 \mathrm{~cm}$. wide, wrapped about the upper arm as near the axilla as possible. To maintain this position and to conserve space, this wide cuff and the narrow cuff for occluding circulation were enclosed in a common cloth casing with two compartments so that the larger cuff both surrounded, and extended distally from, the lower edge of the smaller cuff. Constant pressure in the wide congesting cuff was insured by connecting it with a slow stream of compressed air, passing through a T-tube and standpipe, the latter immersed to the required depth in a column of water. As described 
TABLE I

$P_{\text {moc }}{ }^{*}$ and maximum change in vascular volume determined by Methods $I$, II and III for 20 normal subjects at $34^{\circ} C$.

\begin{tabular}{|c|c|c|c|c|c|c|c|c|c|}
\hline \multirow{2}{*}{$\begin{array}{l}\text { Subject } \\
\text { number }\end{array}$} & \multirow[b]{2}{*}{ Sex } & \multirow[b]{2}{*}{ Age } & \multirow{2}{*}{$\begin{array}{l}\text { Arterial } \\
\text { blood } \\
\text { pressure }\end{array}$} & \multicolumn{2}{|c|}{ Method I } & \multicolumn{2}{|c|}{ Method II } & \multicolumn{2}{|c|}{ Method III } \\
\hline & & & & $P_{\text {mue }}$ & $\begin{array}{c}\text { Maximum } \\
\text { volume } \\
\text { change }\end{array}$ & $P_{\text {moc }}$ & $\begin{array}{c}\text { Maximum } \\
\text { volume } \\
\text { change }\end{array}$ & $P_{m w}$ & $\begin{array}{c}\text { Maximum } \\
\text { volume } \\
\text { change }\end{array}$ \\
\hline & & & & $m m . H_{g}$ & $\begin{array}{l}c c . \text { per } \\
100 \text { cc. } \\
\text { forearm }\end{array}$ & $m m . H_{g}$ & $\begin{array}{l}c c . \text { per } \\
100 \mathrm{cc} . \\
\text { forearm }\end{array}$ & $m m . H g$ & $\begin{array}{l}c c . \text { per } \\
100 c c . \\
\text { forearm }\end{array}$ \\
\hline $\begin{array}{r}1 \\
2 \\
3 \\
4 \\
5 \\
6 \\
7 \\
8 \\
9 \\
10 \\
11 \\
12 \\
13 \\
14 \\
15 \\
16 \\
17 \\
18 \\
19 \\
20\end{array}$ & $\begin{array}{l}\mathbf{M} \\
\mathbf{M} \\
\mathbf{M} \\
\mathbf{M} \\
\mathbf{F} \\
\mathbf{M} \\
\mathbf{M} \\
\mathbf{M} \\
\mathbf{M} \\
\mathbf{F} \\
\mathbf{M} \\
\mathbf{F} \\
\mathbf{F} \\
\mathbf{M} \\
\mathbf{M} \\
\mathbf{M} \\
\mathbf{M} \\
\mathbf{F} \\
\mathbf{M} \\
\mathbf{M}\end{array}$ & $\begin{array}{l}39 \\
20 \\
20 \\
23 \\
27 \\
21 \\
29 \\
27 \\
28 \\
28 \\
26 \\
30 \\
21 \\
31 \\
31 \\
23 \\
24 \\
27 \\
30 \\
23\end{array}$ & $\begin{array}{r}122 / 82 \\
110 / 66 \\
104 / 62 \\
108 / 64 \\
92 / 64 \\
110 / 70 \\
112 / 70 \\
120 / 75 \\
110 / 70 \\
110 / 74 \\
116 / 74 \\
100 / 60 \\
98 / 62 \\
126 / 74 \\
114 / 68 \\
130 / 80 \\
122 / 70 \\
108 / 70 \\
118 / 80 \\
120 / 74\end{array}$ & $\begin{array}{l}20.0 \\
21.5 \\
22.5 \\
22.5 \\
24.0 \\
24.0 \\
25.0 \\
25.0 \\
25.5 \\
26.5 \\
26.5 \\
26.5 \\
27.0 \\
30.0 \\
30.0 \\
31.0 \\
31.5 \\
32.5 \\
33.0 \\
33.0\end{array}$ & $\begin{array}{l}2.07 \\
1.74 \\
1.72 \\
1.68 \\
1.20 \\
1.71 \\
1.46 \\
1.39 \\
1.14 \\
0.95 \\
1.55 \\
0.99 \\
1.45 \\
1.26 \\
1.15 \\
1.45 \\
1.32 \\
0.86 \\
1.36 \\
1.26\end{array}$ & $\begin{array}{l}19.5 \\
16.0 \\
21.0 \\
16.0 \\
21.0 \\
18.5 \\
18.5 \\
18.5 \\
18.0 \\
20.5 \\
21.0 \\
19.0 \\
18.0 \\
23.0 \\
22.0 \\
24.0 \\
28.0 \\
21.0 \\
28.0 \\
23.0\end{array}$ & $\begin{array}{l}2.67 \\
2.59 \\
2.48 \\
2.42 \\
1.65 \\
1.87 \\
1.92 \\
2.04 \\
1.65 \\
1.65 \\
2.15 \\
1.89 \\
2.02 \\
1.81 \\
1.95 \\
2.36 \\
1.78 \\
1.84 \\
2.06 \\
1.81\end{array}$ & $\begin{array}{l}19.0 \\
18.0 \\
17.0 \\
18.0 \\
19.0 \\
23.5 \\
20.0 \\
25.0 \\
19.5 \\
23.0 \\
22.0 \\
20.0 \\
20.0 \\
25.5 \\
22.5 \\
22.0 \\
23.5 \\
25.5 \\
22.0 \\
21.0\end{array}$ & $\begin{array}{l}2.23 \\
1.78 \\
2.28 \\
1.85 \\
1.60 \\
1.62 \\
1.87 \\
1.86 \\
1.58 \\
1.44 \\
1.80 \\
1.72 \\
1.87 \\
1.78 \\
1.68 \\
2.14 \\
1.90 \\
1.79 \\
1.61 \\
1.98\end{array}$ \\
\hline \multicolumn{4}{|c|}{ Averages } & 26.9 & 1.38 & 20.7 & 2.03 & 21.3 & 1.82 \\
\hline \multicolumn{4}{|c|}{ Range of $P_{\text {moe, }} \mathrm{mm} . \mathrm{Hg}$} & \multicolumn{2}{|c|}{$20.0-33.0$} & \multicolumn{2}{|c|}{$16.0-28.0$} & \multicolumn{2}{|c|}{$17.0-25.5$} \\
\hline
\end{tabular}

${ }^{*} P_{m v e}=$ that external pressure at which the vis a tergo of the circulation was able to keep open the greatest collective vascular volume.

previously (5), elevating venous pressure in the vertical forearm to a given level, e.g., $30 \mathrm{~mm}$. $\mathrm{Hg}$, required that the cuff on the horizontal upper arm be inflated to the desired level, e.g., $30 \mathrm{~mm}$. $\mathrm{Hg}$, plus an additional increment equal to the hydrostatic pressure of the column of blood in the vertical veins of the forearm. This increment, determined separately for each observation, was always between 16 and $17 \mathrm{~mm}$. $\mathrm{Hg}$. In the discussion, tables and figures below, only the effective venous pressure in the forearm segment is mentioned, the corresponding armlet pressure being between 16 and $17 \mathrm{~mm}$. $\mathrm{Hg}$ greater.

Figure 5 shows the effect of continuous elevation of venous pressure on the pressure-volume curve and $P_{m v c}$ obtained by Method II in one subject. $P_{m v c}$ was determined in the usual manner and is shown by the figure near each curve. As venous pressure, and therefore capillary blood pressure, were increased, the curves became lower, moved toward the right, and $P_{\text {moo }}$ became higher.

When the effective venous pressure in the forearm was zero, $P_{m v c}$ by Methods I and II (Table II) was within the range observed in the uncon- gested arms of normal subjects. It is noteworthy that at this venous pressure the wide pneumatic cuff was inflated to a pressure of 16 or $17 \mathrm{~mm}$. $\mathrm{Hg}$ and that the veins in the upper arm were distended to some extent even before circulation was shut off completely. The left limb of the curve was more complete than usual but $P_{m v c}$ was still in the normal range, indicating that venous filling per se did not distort $P_{m v c}$ greatly.

As effective venous pressure became higher, $P_{m v c}$ exceeded the imposed venous pressure markedly with the lower grades of venous congestion, and less conspicuously with higher grades of congestion. At the highest level, $50 \mathrm{~mm}$. $\mathrm{Hg}, P_{m v c}$ in only one observation on one subject (female) was lower than the imposed venous pressure by $4 \mathrm{~mm}$. $\mathrm{Hg}$; but, in this one instance, the pressure in the congesting cuff $(67 \mathrm{~mm}$. $\mathrm{Hg}$ ) exceeded diastolic pressure by $5 \mathrm{~mm}$. $\mathrm{Hg}$ so that interference with arterial inflow probably prevented complete congestion in the time available between separate ob- 


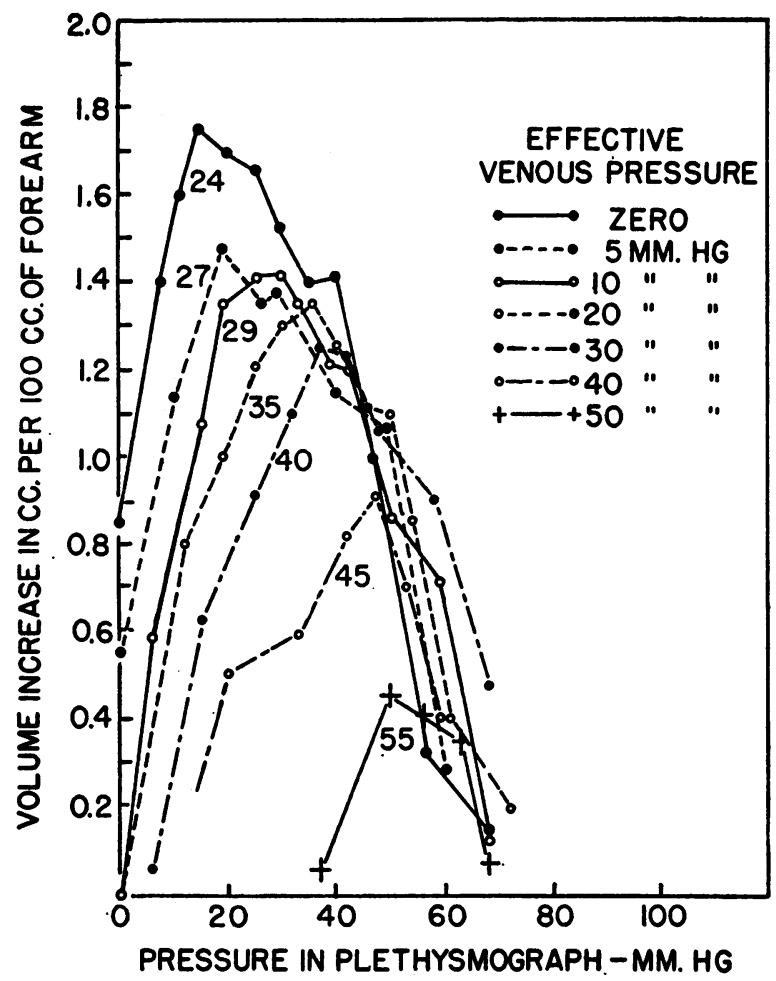

Fig. 5. Showing Effect of Graded Venous Congestion on Pressure-Volume Curves and $P_{m v c}$ of One Subject by Method II

servations. Similar inconsistencies were observed when brief intermittent venous congestion was used.

Comparison of the results by Methods I and II (Table II) indicates again that vascular filling by reactive hyperemia produces slightly greater volume changes and slightly lower $P_{m v c}$ than does simple emptying of vessels when circulation is normal. As would be expected, these slight differences disappear as the level of venous pressure increases and as the capillary bed becomes more completely distended.

With Method III, however, the pressure-volume curves were bizarre and unreadable when effective venous pressure was raised by continuous congestion to $10 \mathrm{~mm}$. $\mathrm{Hg}$ or more. While Methods II and III were similar in measuring volume change during reactive hyperemia, they differed in the degree to which the arm was emptied of blood before volume changes were measured. In Method II, pressure in the plethysmograph was elevated 2 minutes before the brachial artery and veins were occluded. The forearm was therefore partially or completely emptied of blood before the veins of the upper arm were occluded. In Method III, the brachial artery and veins were occluded by inflating the axillary cuff at the same time as pressure in the plethysmograph was raised. The latter pressure then displaced blood into the already distended veins of the upper arm, creating there a pressure considerably above that in the congesting cuff. Deflation of the narrow occluding cuff at the axilla allowed varying quantities of blood to pass immediately under the wide congesting cuff and the volume of the forearm diminished suddenly by an irregular and unpredictable amount, owing to emptying of the overdistended veins. Under these conditions the increase in volume by reactive hyperemia was diminished or even nullified by the simultaneous decrease in volume due to sudden venous emptying. The pressure volume curves were entirely unreliable as recorded in Table II.

The results indicate that while the limited venous reservoir in the upper arm produces little distortion, even by Method III, when venous pressure is normal, this shorter method introduces serious errors and inconsistencies when venous pressure is high. It would seem therefore that in this situation Methods I and II are more reliable. The specific values for $P_{m v c}$ will be compared with directly determined capillary and venous blood pressures below.

\section{The effects of position of the forearm on the pressure-volume curve and on $P_{m v c}$}

The effects of position of the hand on venous (9) and capillary blood pressure (1) are known from previous direct measurements. Changing the position of the forearm relative to the heart changed the pressure-volume curves as illustrated in Figure 6. The number and arrow with each curve gives the corresponding value for $P_{m v c}$.

To raise the mid-point of the forearm $30 \mathrm{~cm}$. above the suprasternal notch (plus $30 \mathrm{~cm}$., Figure 6), the subject was seated in a low chair, the arm was supported vertically, and the plethysmograph was raised as high as possible on its standard. At $0 \mathrm{~cm}$. (Figure 6), the middle of the forearm then being opposite the suprasternal notch, the position was essentially that used routinely and described previously under Methods. To depress the forearm $12 \mathrm{~cm}$. below the suprasternal notch (minus $12 \mathrm{~cm}$., 
Figure 6) the subject was seated and the arm placed horizontally at the side. Maximal dependency of the forearm (minus $35 \mathrm{~cm}$., Figure 6) was obtained by hanging the arm downward and vertically at the side of the seated subject. The plethysmograph was inverted with the wider aperture uppermost. In each position the burette, the burette reservoir, water outlet and manometer (Figure 1, I, K, E, M) were, as usual, placed level with the upper diaphragm of the plethysmograph. When the heavy iron standard could not be used, the plethysmograph, hand and elbow were supported by sandbags. The relation of the forearm to the plethysmograph in these experiments was less stable than in the routine arrangement described in previous sections, but remained constant enough to permit satisfactory readings.

In three determinations by Method III, when the mid-point of the vertical plethysmograph was $30 \mathrm{~cm}$. above the suprasternal notch, the greatest changes in volume ranged from 1.32 to $1.60 \mathrm{cc}$. per $100 \mathrm{cc}$. of arm and were therefore essentially the same as those observed at heart levels, while $P_{\text {moo }}$ was lowered to 10,11 and $12 \mathrm{~mm}$. $\mathrm{Hg}$. At $0 \mathrm{~cm}$. with the middle of the forearm opposite the suprasternal notch, $P_{m v c}$ was $22 \mathrm{~mm}$. $\mathrm{Hg}$ but when the forearm was depressed to between 12 and 13 $\mathrm{cm}$. below its usual position, $P_{m v c}$ rose to 34 and $34.5 \mathrm{~mm}$. $\mathrm{Hg}$ by Method II. The pressure-volume curve in this latter position resembled in configuration and amplitude those resulting from an effective venous congestion of $10 \mathrm{~mm} . \mathrm{Hg}$ in the routine position.

When the forearm was situated $20 \mathrm{~cm}$. below the suprasternal notch, $P_{m v c}$ was 39 and $41.5 \mathrm{~mm}$. $\mathrm{Hg}$. Increasing this distance to between 35 and $40 \mathrm{~cm}$. elevated $P_{m v c}$ to 52 and $50 \mathrm{~mm}$. $\mathrm{Hg}$ by Method I and $44 \mathrm{~mm}$. $\mathrm{Hg}$ by Method II. The greatest dependency obtainable was $45 \mathrm{~cm}$. and $P_{m v c}$ by Method I then became 72, 68 and $68 \mathrm{~mm}$. $\mathrm{Hg}$ and 51,52 and $57 \mathrm{~mm}$. $\mathrm{Hg}$ by Method II. At these levels the maximal volume changes were greater than those noted when venous pressure was elevated to the same degree by means of the pneumatic cuff, and the curves were less regular because the relation between the forearm and the plethysmograph could not be kept absolutely constant. As with high grades of venous congestion

TABLE II

Effects of venous congestion on $P_{m v e}$ and maximal change in vascular volume at $34^{\circ} \mathrm{C}$.

\begin{tabular}{|c|c|c|c|c|c|c|c|c|c|c|c|}
\hline \multirow{2}{*}{$\begin{array}{l}\text { Effective } \\
\text { venous } \\
\text { pressure }\end{array}$} & \multicolumn{3}{|c|}{ Method I } & \multicolumn{3}{|c|}{ Method II } & \multicolumn{3}{|c|}{ Method III } & \multicolumn{2}{|c|}{$\begin{array}{c}\text { Average } \\
\text { Methods I, II }\end{array}$} \\
\hline & $\begin{array}{l}\text { Subject } \\
\text { number }\end{array}$ & $P_{m v e}$ & $\begin{array}{c}\text { Maximal } \\
\text { volume } \\
\text { change }\end{array}$ & $\begin{array}{l}\text { Subject } \\
\text { number }\end{array}$ & $P_{\text {mos }}$ & $\begin{array}{c}\text { Maximal } \\
\text { volume } \\
\text { change }\end{array}$ & $\begin{array}{l}\text { Subject } \\
\text { number }\end{array}$ & $P_{m \infty}$ & $\begin{array}{c}\text { Maximal } \\
\text { volume } \\
\text { change }\end{array}$ & $P_{m e x}$ & $\begin{array}{c}\text { Maximal } \\
\text { volume } \\
\text { change }\end{array}$ \\
\hline Zero* & $\begin{array}{r}5 \\
15\end{array}$ & $\begin{array}{c}m m . \mathrm{Hg}_{\mathrm{g}} \\
29.0 \\
29.0\end{array}$ & $\begin{array}{c}c c . \text { per } \\
100 \text { cc. } \\
\text { forearm } \\
1.05 \\
1.05\end{array}$ & $\begin{array}{r}5 \\
15\end{array}$ & $\begin{array}{c}m m . H_{g} \\
21.0 \\
24.5\end{array}$ & $\begin{array}{c}c c . \text { per } \\
100 \text { cc. } \\
\text { forearm } \\
1.41 \\
1.75\end{array}$ & $\begin{array}{l}5 \\
7\end{array}$ & $\begin{array}{c}m m . H g \\
28.0 \\
32.0\end{array}$ & $\begin{array}{c}c c . \text { per } \\
100 \text { cc. } \\
\text { forearm } \\
1.44 \\
1.20\end{array}$ & $\begin{array}{c}m m . H g \\
25.5\end{array}$ & $\begin{array}{l}c c . \text { per } \\
100 \text { cc. } \\
\text { forearm } \\
1.32\end{array}$ \\
\hline $5 \mathrm{~mm} . \mathrm{Hg}$ & $\begin{array}{r}5 \\
15\end{array}$ & $\begin{array}{l}29.0 \\
34.0\end{array}$ & $\begin{array}{l}1.09 \\
0.86\end{array}$ & $\begin{array}{r}5 \\
15\end{array}$ & $\begin{array}{l}22.0 \\
27.0\end{array}$ & $\begin{array}{l}1.52 \\
1.48\end{array}$ & $\begin{array}{l}5 \\
7\end{array}$ & \multicolumn{2}{|c|}{\begin{tabular}{|c|r}
\multicolumn{3}{|c}{ Unreliable } \\
30.0 & 1.47 \\
\end{tabular}} & 28.4 & 1.28 \\
\hline $10 \mathrm{~mm} . \mathrm{Hg}$ & $\begin{array}{r}5 \\
15\end{array}$ & $\begin{array}{l}33.0 \\
37.5\end{array}$ & $\begin{array}{l}0.93 \\
0.83\end{array}$ & $\begin{array}{r}5 \\
15\end{array}$ & $\begin{array}{l}31.0 \\
29.0\end{array}$ & $\begin{array}{l}1.31 \\
1.42\end{array}$ & $\begin{array}{r}5 \\
5 \\
15 \\
21\end{array}$ & \multicolumn{2}{|c|}{$\begin{array}{l}\text { Unreadable } \\
\text { Unreliable } \\
\text { Unreliable } \\
\text { Unreliable }\end{array}$} & 32.6 & 1.12 \\
\hline $20 \mathrm{~mm} . \mathrm{Hg}$ & $\begin{array}{r}5 \\
15\end{array}$ & $\begin{array}{l}33.0 \\
38.5\end{array}$ & $\begin{array}{l}1.10 \\
0.81\end{array}$ & $\begin{array}{r}5 \\
15\end{array}$ & $\begin{array}{l}32.0 \\
35.0\end{array}$ & $\begin{array}{l}1.35 \\
1.36\end{array}$ & $\begin{array}{r}5 \\
21\end{array}$ & \multicolumn{2}{|c|}{$\begin{array}{l}\text { Unreadable } \\
\text { Unreadable }\end{array}$} & 34.6 & 1.16 \\
\hline $30 \mathrm{~mm} . \mathrm{Hg}$ & $\begin{array}{r}5 \\
15\end{array}$ & $\begin{array}{l}39.5 \\
48.0\end{array}$ & $\begin{array}{l}0.99 \\
0.78\end{array}$ & $\begin{array}{r}5 \\
15\end{array}$ & $\begin{array}{l}35.0 \\
40.5\end{array}$ & $\begin{array}{l}0.99 \\
1.26\end{array}$ & $\begin{array}{r}5 \\
7 \\
15\end{array}$ & \multicolumn{2}{|c|}{$\begin{array}{l}\text { Unreadable } \\
\text { Unreadable } \\
\text { Unreadable }\end{array}$} & 40.8 & 1.00 \\
\hline $40 \mathrm{~mm} . \mathrm{Hg}$ & $\begin{array}{r}5 \\
15\end{array}$ & $\begin{array}{l}44.0 \\
49.0\end{array}$ & $\begin{array}{l}0.51 \\
0.68\end{array}$ & $\begin{array}{r}5 \\
15\end{array}$ & $\begin{array}{l}44.0 \\
45.0\end{array}$ & $\begin{array}{l}0.51 \\
0.91\end{array}$ & $\begin{array}{r}5 \\
15\end{array}$ & \multicolumn{2}{|c|}{$\begin{array}{l}\text { Unreadable } \\
\text { Unreadable }\end{array}$} & 45.5 & 0.65 \\
\hline $50 \mathrm{~mm} . \mathrm{Hg}$ & $\begin{array}{r}5 \\
7 \\
15\end{array}$ & $\begin{array}{l}46.0 \\
55.0 \\
57.0\end{array}$ & $\begin{array}{l}0.43 \\
0.49 \\
0.42\end{array}$ & $\begin{array}{r}5 \\
7 \\
-15\end{array}$ & $\begin{array}{l}\text { Unre } \\
55.0 \\
55.0\end{array}$ & $\begin{array}{c}\text { able } \\
0.51 \\
0.46\end{array}$ & $\begin{array}{r}5 \\
15\end{array}$ & \multicolumn{2}{|c|}{$\begin{array}{l}\text { Unreadable } \\
\text { Unreadable }\end{array}$} & 53.6 & 0.46 \\
\hline
\end{tabular}

* Hydrostatic pressure in vertical forearm veins balanced by equal pressure in congesting cuff. 


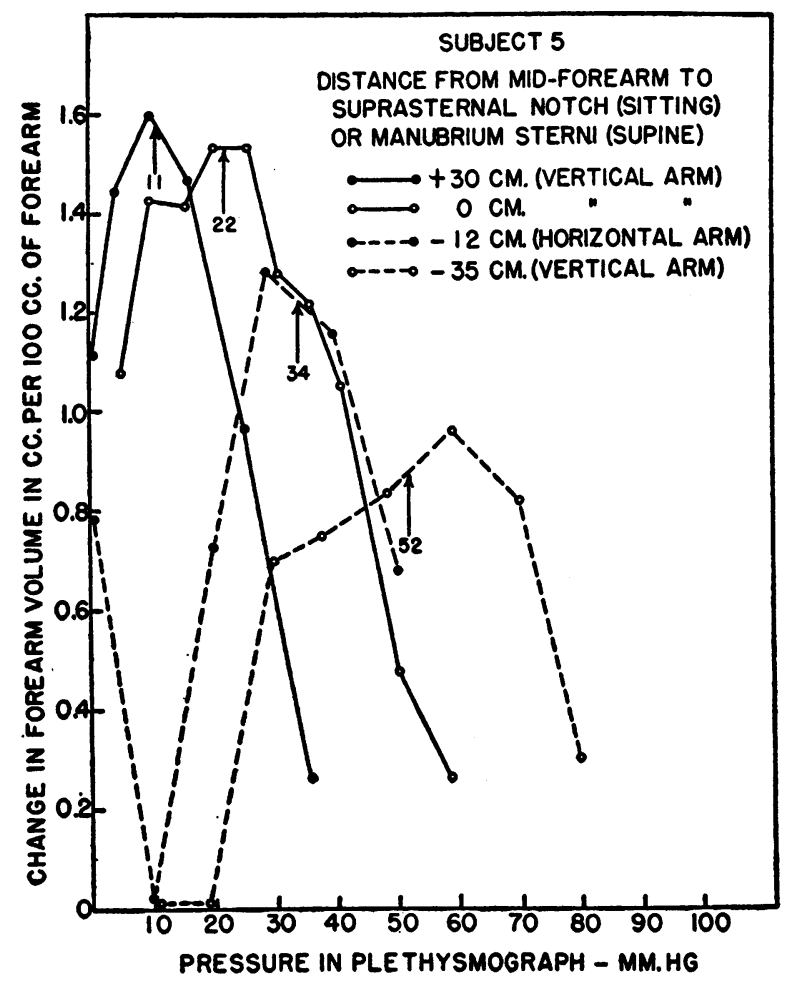

Fig. 6. Showing Effect of Position of the Forearm on Pressure-Volume Curves and $P_{\text {moc }}$

by the pneumatic cuff, Method III yielded bizarre curves in the lowest positions, without a clear maximum, due, it is believed, to the same overdistention of the arm veins which was described in the previous section.

It appears that $P_{\text {mvc }}$ is diminished by elevating the forearm and increased by depressing the forearm and that in these positions the observed values of $P_{\text {mvo }}$ are of the same order of magnitude as those observed with corresponding venous congestion.

\section{Comparison of total vascular volume and "dynamic vascular volume" in relation to venous congestion}

Venous congestion, as is well known, increases total vascular volume because the veins and capillaries are distended by greater internal pressure. Since increasing venous congestion progressively lowered, rather than raised, the peaks of the pressure-volume curves described in the previous two sections, it is obvious that something less than total vascular volume is being measured.
To this volume we have applied the term "dynamic vascular volume" for three reasons: $(a)$ it exists when arterial flow is present and disappears when arterial and venous blood flow are interrupted; $(b)$ it is affected in characteristic manner by external pressure as shown by the preceding pressure-volume curves; and (c) venous congestion, while increasing total vascular volume, induces stasis, decreases blood flow and also decreases this "dynamic vascular volume." The combined effect of venous congestion and external pressure on total vascular volume is shown in Figure 7, to contrast with the curves of "dynamic vascular volume" shown in Figures 3 to 6.

In these observations the forearm was in the usual position with narrow pneumatic cuffs around the wrist and as close as possible to the axilla. Just below the axillary cuff was wrapped a separate wide pneumatic cuff for producing venous congestion. The double cuff could not be used because inflation of the small cuff prevented entrance of air into the large cuff. At zero time, the wrist cuff was inflated to $300 \mathrm{~mm}$. $\mathrm{Hg}$ as usual; simultaneously the pressure in the plethysmograph was elevated to $200 \mathrm{~mm}$. Hg for the purpose of collapsing and evacuating the blood vessels in the forearm as completely as possible. Because the veins in the arm were still open, this blood entered the systemic circulation. At 2:00 minutes the cuff at the axilla was inflated to $300 \mathrm{~mm}$. $\mathrm{Hg}$ to keep the forearm bloodless. Immediately thereafter the plethysmograph pressure was reduced to 0 or 10 or 20 , etc., $\mathrm{mm} . \mathrm{Hg}$, and the large congesting cuff was simultaneously inflated to the desired venous pressure, 0 or 10 or 20, etc., mm. Hg. At 3:00 minutes the volume of water in the burette was recorded; circulation was then released. The peak volume reached during reactive hyperemia was recorded. The difference between the 2 readings indicated total vascular volume during various combinations of venous congestion and external pressure as shown in Figure 7, the vessels having been emptied as much as possible previously.

At all venous pressures the greatest volume was observed when external pressure was zero, and all these volumes were greater than those observed in any of the previous experiments. When effective venous congestion was zero, the pressurevolume curve passed through a slight plateau at pressures of 10 to $30 \mathrm{~mm}$. $\mathrm{Hg}$, and then fell off steeply at higher external pressures. Increasing congestion to $10 \mathrm{~mm}$. $\mathrm{Hg}$ merely emphasized the plateau, and congestion of $20 \mathrm{~mm}$. $\mathrm{Hg}$ shifted the plateau toward higher pressures. Congestion to $30 \mathrm{~mm}$. $\mathrm{Hg}$ produced definite distortion to a more 
nearly sigmoid curve which became completely sigmoid when the congestion reached $40 \mathrm{~mm}$. $\mathrm{Hg}$. It is of interest to recall that Lewis (7) found 30 $\mathrm{mm}$. Hg the lowest congesting pressure which could produce detectable reactive hyperemia in the forearm, suggesting that this pressure was the lowest to interfere with capillary blood flow.

This indicates that, even when "total vascular volume" is measured, the configuration of the pressure-volume curve is altered distinctively when external pressure reaches that level believed to exist in the minute vessels, providing venous congestion is not great enough to obliterate the normal gradient of blood pressure in the capillary network. When congestion is extreme and extends throughout the capillary bed, the curve is that to be expected when external pressure acts upon an elastic system which is distended by uniform pressure in all its parts.

That this total vascular volume differs slightly from "dynamic vascular volume," even when no venous congestion is present, is illustrated by the insert in Figure 7 in which these two pressurevolume curves are superimposed. They are similar above $20 \mathrm{~mm}$. $\mathrm{Hg}$ but below that level "dynamic vascular volume" becomes less, probably because the arm has not been previously emptied of blood. A comparison of Figures 5 and 7 indicates, however, that "dynamic vascular volume" affords a more revealing estimate of the interaction of vis a tergo, effective intravascular pressure, and volume of blood actually in movement, while excluding from measurement that volume of blood which is in stasis due to congestion.

\section{Comparison of $P_{m v c}$ with direct determinations of capillary blood pressure and venous blood pressure}

The method of determining $P_{m v c}$ was adopted for theoretical reasons before, and not after, the detailed comparison in Table III was made. Though the pressure-volume curves and $P_{m v c}$ are entirely objective values, nevertheless the meaning of this or any other arbitrarily chosen criterion must be tested by comparing its results with those of the micro-injection method, the latter being the most accurate procedure so far available for determining capillary blood pressure (3). As shown in Table III, in the resting state with the forearm

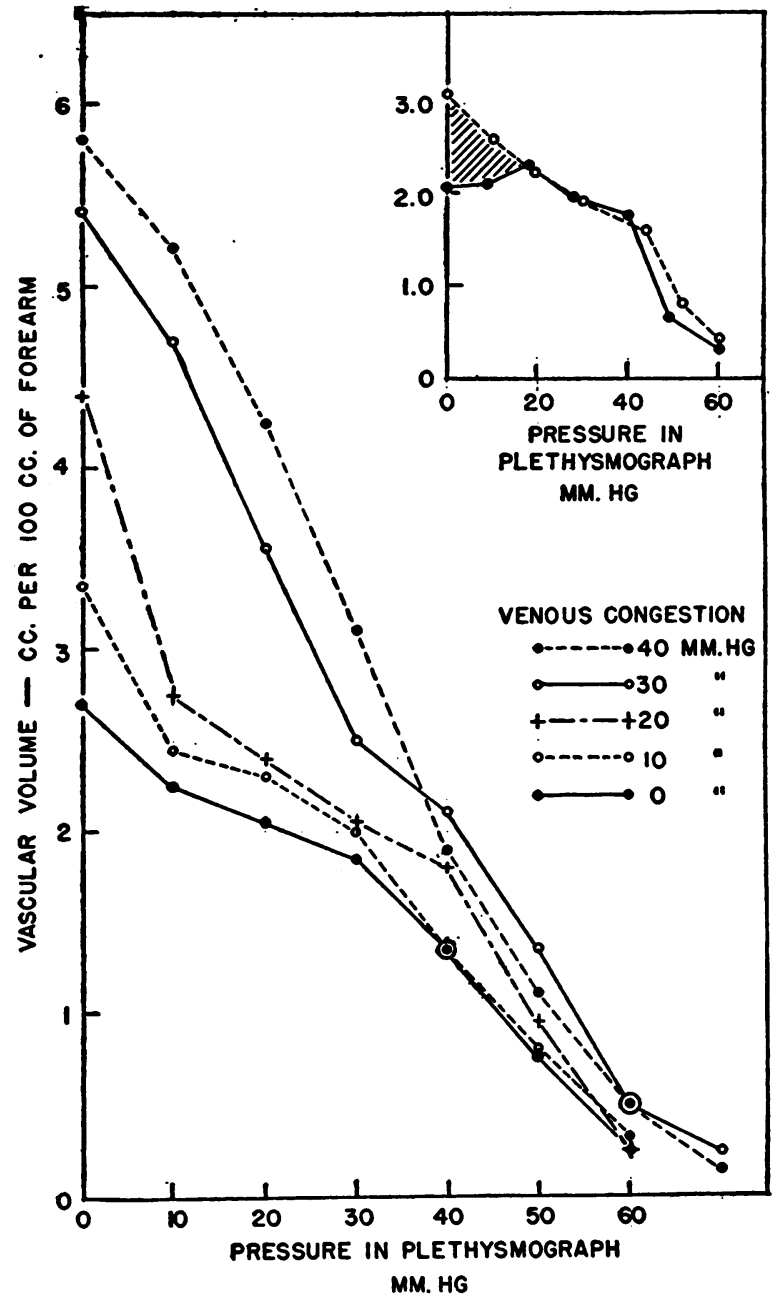

Fig. 7. Showing Effect of Venous Congestion and External Pressure on Total Vascular Volume AvERAGE FOR 2 SUBJECTS

Inset compares total vascular volume (circles and broken line) and "dynamic vascular volume" (dots and solid line) at normal venous pressure.

at heart level, average $P_{m v c}$ ranged, according to method used, from 17 to $33 \mathrm{~mm}$. $\mathrm{Hg}$ with average values of 21 to $27 \mathrm{~mm}$. $\mathrm{Hg}$. By Method II, $P_{m v c}$ ranged from 16 to $28 \mathrm{~mm}$. $\mathrm{Hg}$ with $21 \mathrm{~mm}$. $\mathrm{Hg}$ as average, while the figures by micro-injection (1) ranged from 6 to $48 \mathrm{~mm}$. $\mathrm{Hg}$, with $22 \mathrm{~mm}$. $\mathrm{Hg}$ as average. Since the plethysmographic measurements included all the peripheral vessels, the micro-injection values for both limbs of the capillary loop have been grouped together. Whether mean values or extremes are compared, $P_{m v c}$ in the normal subject has the same order of magni- 
TABLE III

Comparison of $P_{m v c}$ with capillary blood pressure determined directly $(1,2,3)$

\begin{tabular}{l|r|c|c|c}
\hline \hline & Method & $P_{\text {mvo }}$ & $\begin{array}{c}\text { Capillary } \\
\text { bleod } \\
\text { pressure } \\
\text { by micro- } \\
\text { injection }\end{array}$ & $\begin{array}{c}\text { Refer- } \\
\text { ence }\end{array}$ \\
\hline $\begin{array}{c}\text { Resting state with } \\
\text { extremity at } \\
\text { heart level }\end{array}$ & II & $\begin{array}{c}27(20-33) \\
21(16-28) \\
\text { III }\end{array}$ & $\begin{array}{c}21(17-26) \\
21(6-48)\end{array}$ & (1) \\
\hline
\end{tabular}

\begin{tabular}{|c|c|c|c|c|c|}
\hline & $\begin{array}{l}\text { Venous } \\
\text { pres- } \\
\text { sure }\end{array}$ & $P_{m v 0}$ & $\begin{array}{l}\text { Ve- } \\
\text { nous } \\
\text { pres- } \\
\text { sure }\end{array}$ & $\begin{array}{c}\text { Capil- } \\
\text { lary } \\
\text { blood } \\
\text { pres- } \\
\text { sure }\end{array}$ & \\
\hline $\begin{array}{l}\text { Elevated venous } \\
\text { pressure (con- } \\
\text { gestion) }\end{array}$ & $\begin{array}{c}\underset{H \boldsymbol{g}}{m m} . \\
10 \\
\\
20 \\
30 \\
40 \\
\\
50\end{array}$ & $\begin{array}{c}\underset{H g}{m m} . \\
29-37 \\
\\
32-39 \\
35-48 \\
44-49 \\
\\
55-57\end{array}$ & $\begin{array}{c}m m_{g} \\
10 \\
12 \\
24 \\
27 \\
40 \\
45 \\
47 \\
52 \\
60\end{array}$ & $\begin{array}{r}\underset{H g}{\operatorname{mm}} . \\
\mathbf{H g} \\
25,35 \\
25 \\
41 \\
35 \\
48-50 \\
47 \\
50-56 \\
58-68 \\
60-76\end{array}$ & $\begin{array}{c}(2) \\
(2) \\
(2) \\
(2) \\
(1) \\
(3) \\
(3) \\
(3) \\
(1,3)\end{array}$ \\
\hline
\end{tabular}

\begin{tabular}{|c|c|c|c|c|c|}
\hline & $\begin{array}{c}\text { Posi- } \\
\text { tion of } \\
\text { forearm }\end{array}$ & $P_{\text {mve }}$ & $\begin{array}{c}\text { Posi- } \\
\text { tion } \\
\text { of } \\
\text { finger }\end{array}$ & \begin{tabular}{|c} 
Capil- \\
lary \\
blood \\
pres- \\
sure
\end{tabular} & \\
\hline $\begin{array}{l}\text { Change in posi- } \\
\text { tion relative to } \\
\text { suprasternal } \\
\text { notch (plus } \\
\text { above, minus } \\
\text { below) }\end{array}$ & $\begin{array}{r}c m . \\
+30 \\
0 \\
-12 \\
-20 \\
-35 \\
-40 \\
-45\end{array}$ & $\begin{array}{c}\underset{H m .}{\operatorname{mm} .} \\
10-12 \\
21-27 \\
27-35 \\
39-42 \\
44-52 \\
44-50 \\
51-68\end{array}$ & $\begin{array}{r}-32 \\
0 \\
18 \\
40\end{array}$ & $\begin{array}{c}\underset{H g}{m m} . \\
6-26 \\
7-44 \\
17-52 \\
30-62\end{array}$ & $\begin{array}{l}(1) \\
(1) \\
(1) \\
(1)\end{array}$ \\
\hline
\end{tabular}

tude as the directly determined values of capillary blood pressure.

The same holds true when the comparison is extended to the observations in which capillary blood pressure was diminished by raising the forearm, or increased by venous congestion and lowering the forearm. However, even when the observations of Landis (1), Fahr and Ershler (2), and Eichna and Bordley (3) are pooled, they are not numerous enough to justify computing averages, so that only the range of individual determinations is given in the lower 2 sections of Table III. Elevation of venous pressure to 10 or $20 \mathrm{~mm}$. Hg affected capillary blood pressure and $P_{m o c}$ less than did greater increments of venous pressure. In both series the amount by which the determined values exceeded venous pressure was greater with mild congestion than with severe congestion, as would be expected because of the gradient of pressure believed to exist in the capillary network.

In the present study, venous pressure was also measured directly in the horizontal arm at the antecubital space in 5 subjects before and after circulation was occluded by the axillary cuff. Before occlusion, venous pressure ranged from 7.5 to $9.0 \mathrm{~mm}$. $\mathrm{Hg}$, averaging $8.0 \mathrm{~mm}$. $\mathrm{Hg}$. In agreement with Kendrew (8) it was found that inflation of the narrow cuff below the axilla increased venous pressure, which then ranged from 10.5 to $16.5 \mathrm{~mm}$. $\mathrm{Hg}$, with an average of 13.5 $\mathrm{mm}$. $\mathrm{Hg}$. In a single observation on one subject the venous pressure taken twice in succession in the occluded arm was 20.0 and $24.5 \mathrm{~mm}$. $\mathrm{Hg}$ while in a third measurement a few moments later it was 15.5. Since these first two exceptionally high values were followed by one in the more usual range it seems likely that the movement of fluid from the manometer to the vein was not entirely free and they have been excluded from the above average. Release of the cuff, after 2 minutes of complete ischemia, reduced venous pressure at the antecubital space immediately to an average of $8.5 \mathrm{~mm} . \mathrm{Hg}$, even during reactive hyperemia.

Venous pressure could not be measured in the forearm itself in the vertical position. However, this pressure in the vertical forearm would certainly be considerably less than the $13.5 \mathrm{~mm}$. $\mathrm{Hg}$ observed in the antecubital space. These estimations of venous pressure may explain in part why $P_{m v c}$ by Method I amounted to $27 \mathrm{~mm}$. $\mathrm{Hg}$ as compared to $21 \mathrm{~mm}$. $\mathrm{Hg}$ by Methods II and III. In Method I the change in vascular volume of the forearm was measured while the axillary cuff was inflated, and any blood expressed from the forearm met an average initial resistance of $13.5 \mathrm{~mm} . \mathrm{Hg}$ rather than the normal venous pressure of $8.0 \mathrm{~mm}$. Hg. On the contrary, in Methods II and III the axillary cuff was deflated, the veins were open, and the venous pressure was $8.5 \mathrm{~mm}$. $\mathrm{Hg}$, or lower than before by $5.0 \mathrm{~mm}$. $\mathrm{Hg}$. The discrepancy between $P_{m v c}$ by Method I and Methods II and III is almost exactly equal to this difference in venous pressure. 
The comparison with venous pressure can be extended also to the measurements made when the forearm was elevated above, or depressed below, heart level. In the former position Carrier and Rehberg (9) found venous pressure was 3.5 $\mathrm{mm}$. $\mathrm{Hg}$, whereas $P_{\text {mvc }}$ determined plethysmographically ranged from 10 to $12 \mathrm{~mm}$. $\mathrm{Hg}$. Therefore, in whatever position the forearm was placed $P_{m v c}$ was definitely higher than venous pressure and had the same order of magnitude as capillary blood pressure.

\section{DISCUSSION}

The significance of the pressure-volume curves and of $P_{m v c}$, as described in this paper, depends upon (1) the collective volume of the capillary network compared to that of the venules and arterioles; (2) the accuracy with which pressure is transmitted from the plethysmograph, through the tissues, to the blood within the vessels; (3) the magnitude of errors arising from the effect of external pressure on extravascular fluid; (4) the effect of low external pressures on the volume of the capillary network by reason of passive congestion produced by partial compression of veins ; (5) the part played by the capacity of veins in the upper arm during the occlusion of circulation; and $(6)$ the relation of the pressure-volume curves and $P_{m v c}$ to known changes in venous and capillary blood pressures under various conditions.

(1) As blood flows through the peripheral vessels, it enters first the arteries and larger arterioles where cross-sectional area is small, pressure is high, and flow is rapid. In the capillaries, crosssectional area becomes relatively enormous while pressure and rate of flow diminish. Finally in the veins, the cross-sectional area again diminishes, pressure reaches its lowest level, and the rate of flow once more increases. Concerning the comparative collective volumes of these sections of the vascular tree in the extremities, there is little quantitative information, but from what is known of circulation time and the total capillary volume, it can hardly be questioned that the minute arterioles, the true capillaries and the venous capillaries have a total volume greater than that of the other subdivisions of the vascular tree. From photomicrographs of the vessels in the frog's mesentery previously published (10), computation shows that one terminal arteriole gave rise to a series of arteriolar capillaries whose total volume was at least ten times as great as that of the parent vessel, and it seems likely that venous capillaries would contribute an equal, if not greater, volume.

When pressure is applied externally to a system as complicated as this, there must follow a series of changes which cannot be divided into definite stages because they merge gradually into each other. If increasing pressure is applied to the surface of the skin, for instance by a capsule, the first change observed is a flattening of veins while blood flow still continues through the partially collapsed vessels. It has been shown (11) that even this partial collapse produces slight but definite passive congestion in the capillary area drained by the vein, even though the applied external pressure is still below venous pressure. As external pressure is increased further, to between 5 and $15 \mathrm{~mm}$. $\mathrm{Hg}$, the skin blanches owing to compression of the subpapillary venous plexus. Higher pressures, possibly in the vicinity of 15 to $45 \mathrm{~mm}$. $\mathrm{Hg}$, compress the true capillaries and still more pressure is required to compress larger arterioles, e.g., in the retina. While many studies describe the visible effects of external pressure on these vessels, no observations have been found which measure effects on collective vascular volume.

Because the peripheral blood vessels present various combinations of pressure and volume, it was expected that the pressure-volume curves might show a characteristic configuration. In simplest terms low external pressures, just sufficient to compress the veins partially, might produce either a relatively small decrease in vascular volume or, if capillary congestion and passive distention were significant, a slight increase in net vascular volume. In either case, however, when external pressure becomes great enough to impinge on the capillary vessels and the smallest arterioles, vascular volume should decrease conspicuously. Pressures above this level would make the forearm relatively bloodless because only the larger arterioles and arteries could remain filled. Conversely, if external pressure were gradually lowered from $120 \mathrm{~mm}$. $\mathrm{Hg}$, the most striking increase in vascular volume would be expected when external pressure became low enough to 
permit the arteriolar capillaries throughout the forearm segment to fill, reaching a maximum when external pressure was low enough to permit the greatest volume of capillaries and minute arterioles to fill.

In the normal forearm, elevating external pressure from 0 to $15 \mathrm{~mm}$. $\mathrm{Hg}$ increased "dynamic vascular volume" slightly or conspicuously depending upon the method used. Maximal vascular volumes were observed at pressures between 15 and $30 \mathrm{~mm}$. $\mathrm{Hg}$, while beyond that point "dynamic vascular volume" fell off sharply. In the average curves of Figure 4 and in some individual curves of Figure 3 , it is obvious that increasing external pressure to $15,20,25$ and $30 \mathrm{~mm}$. $\mathrm{Hg}$ permitted approximately the same volume of blood to remain in the forearm, producing little or no collapse of the minute vessels. This is to be expected by reason of the average gradient of pressure in the resting capillary network of man (1). According to the direct micro-injection method this gradient on the average falls in the same pressure range, namely, from $32 \mathrm{~mm}$. $\mathrm{Hg}$ in the arteriolar capillaries to $12 \mathrm{~mm}$. $\mathrm{Hg}$ in the venous capillaries.

It might be objected that the configuration of the pressure-volume curves was related not to the pressure existing in the resting minute vessels but to progressive arteriolar dilatation in response to the obstruction of blood flow by progressive increments of external pressure. Lewis (7) has shown clearly, however, that when external pressures up to $30 \mathrm{~mm}$. $\mathrm{Hg}$ are applied to the skin, no reactive hyperemia, i.e., no dilatation of the minute vessels, can be detected and concluded therefrom that up to this pressure, blood flow was not impeded significantly. At external pressures of 40 to $65 \mathrm{~mm}$. $\mathrm{Hg}$ reactive hyperemia is faint and patchy and slight dilatation can be detected plethysmographically. Only when the imposed pressure approaches diastolic arterial pressure, e.g., 65 to $85 \mathrm{~mm}$. $\mathrm{Hg}$, is reactive hyperemia conspicuous and volumetric change considerable. Therefore, if progressive arteriolar dilatation were responsible for the volume curves produced by increasing external pressure, the volume of blood in the forearm should remain constant, or actually increase, up to pressures of 65 or $85 \mathrm{~mm}$. $\mathrm{Hg}$, whereas it usually falls off distinctly when external pressure reaches $35 \mathrm{~mm}$. Hg. Moreover, methods II and III, unlike method I, required complete cessation of flow for 2 minutes and produced slight but definite reactive hyperemia. The volume curves were not displaced toward higher pressures.

The pressure-volume curves described are also distinct from the more familiar "oscillometric curves" which measure the effect of external pressure on the pulsation of the vessels in a segment of tissue. In 2 subjects the ascending limb of the oscillometric curve was found to start at external pressures which reduced the pressurevolume curve almost to zero. The peak of the oscillometric curve was situated near diastolic arterial blood pressure, while the peaks of the pressure-volume curves appeared at a much lower level.

(2) The accuracy with which pressure is transmitted from the plethysmograph through the tissues to the blood within the vessels has been tested. Changing the venous pressure by 0.5 to 1 $\mathrm{mm}$. $\mathrm{Hg}$ produced immediate and measurable change in the volume of the forearm when external pressure was lower than the venous pressure concerned. If pressure in the plethysmograph was greater than the venous pressure at which the change was induced, little or no change in vascular volume could be detected. Conversely, if the veins at the axilla were blocked beforehand, changing the pressure in the plethysmograph produced corresponding changes in venous pressure. It appears that the relaxed tissues of the forearm transmitted pressure quite accurately.

(3) Errors might arise conceivably from the effect of external pressure on the volume of extravascular fluid. However, Landis and Gibbon (5) observed that an external pressure of 200 $\mathrm{mm}$. $\mathrm{Hg}$ produced insignificant change in the volume of extravascular fluid. Since the observations discussed in this paper involved lower pressures and brief periods, this error was negligible. Moreover, if this factor were important, it would be expected that the greatest volume changes would have occurred at higher pressures, whereas the opposite was found.

(4) It is known that partial compression of a vein, by pressure somewhat lower than venous pressure, will obstruct venous flow slightly and 
produce slight but definite passive congestion in the immediately connected capillary network (11). Applying to the surface of the forearm a pressure approximating venous pressure might have elevated capillary blood pressure and passively distended the capillary vessels. To test this possibility, pressure was applied to the arteries, capillaries and veins of the frog's mesentery by means of a large capsule covered by a transparent, flexible membrane. These observations verified the earlier finding that pressures lower than venous pressure would flatten a vein slightly and interfere with venous return. Slight stasis appeared in some capillaries but no measurable increase in volume could be detected, though flattening of the capillaries increased the transverse diameter in some instances. It appears that low external pressures, because they impinge upon veins and capillaries alike, do not increase capillary volume greatly even when flow is modified. Higher pressures, of course, diminshed both venous and capillary volumes very obviously. These observations emphasized the overlapping effects of pressure in that a capsular pressure barely sufficient to obliterate one venule would leave another venule partly open, compress a few capillaries visibly, and leave the majority unaffected. Increasing the external pressure would advance these effects toward the arterioles successively, but far from uniformly, when individual vessels were observed. This accords with the highly variable pressures observed in separate capillaries even when they arise from the same arteriole (10) and lends support to the thesis that measuring changes in collective volume may integrate the infinitesimal and variable volume changes in single vessels.

(5) The limited capacity of the veins in the upper arm may conceivably have made Method I yield systematically high results. In the resting forearm Methods II and III were not complicated by this factor since the veins were open when readings were made. Though the veins in Method III were fuller than in Method II, the pressurevolume curves and $P_{m v c}$ were almost identical, indicating that in the normal forearm slight differences in prior filling of the veins did not influence the pressure-volume relationships observed during subsequent reactive hyperemia. When venous pressure is high, however, greater prior filling of the veins makes Method III unreliable.
Also against the existence of any serious artifacts in Methods I and II due to the limited venous reservoir in the upper arm, are observations in which "dynamic vascular volume" was determined during digital compression of the brachial or the subclavian artery. Because of the difficulty of ensuring complete and uniform arterial occlusion for 2 minutes by digital pressure, this method was abandoned but enough observations were made to demonstrate that the pressure-volume curves and $P_{m v c}$ were qualitatively similar to those obtained by Methods I and II. In these experiments the venous return from the arm was never shut off completely.

(6) The relation of the pressure-volume curves and $P_{m v c}$ to known changes in venous and capillary blood pressures has been summarized in Table III. It seems clear that $P_{m v c}$ in the normal and the congested forearm follows capillary blood pressure rather than venous pressure.

Though roughly similar in this respect, the pressure-volume curves by Methods I and II differ slightly and systematically. $P_{m v c}$ by Method I was $27 \mathrm{~mm}$. $\mathrm{Hg}$, by Method II, $21 \mathrm{~mm}$. $\mathrm{Hg}$. In Method I while the measured "dynamic vascular volumes" were those of resting circulation, the limited volume of the occluded veins of the upper arm may have made the observed $P_{m v c}$ slightly higher than the true intravascular pressure in the minute vessels. In Method II the limitations of a closed venous reservoir were avoided but the "dynamic vascular volumes" were measured during very mild reactive hyperemia. The error due to reactive hyperemia appears to be a minor one because prolonging the interval of total occlusion to as much as 8 minutes did not modify $P_{m v c}$ even though the maximal change in vascular volume at pressures of 20 to $30 \mathrm{~mm}$. Hg was greater than that observed after 2 minutes' occlusion.

The slightly higher $P_{m v c}$ observed by Method I may also be due in part to the position of the left limb of the pressure-volume curve. In Method I the left limb usually originated at a point between zero and the line marking the upper quarter of volume change, whereas in Methods II and III the left limb originated sometimes above the quarter mark. In the latter, the lower of the two pressures from which $P_{m v c}$ was calculated was often zero, whereas in Method I it was always 5 or more $\mathrm{mm}$. Hg. This difference may have 
been due to the previously mentioned limited capacity of the veins in the upper arm, or to distention of the relaxed venules and veins by the sudden inrush of blood in reactive hyperemia (7). In any case, it does not explain entirely the $6 \mathrm{~mm}$. difference in $P_{m v c}$ because the right limbs of the curves are also displaced toward lower pressures by mild reactive hyperemia. The difference is real since it was observed uniformly in repeated trials on the same subjects at widely separated time intervals. The configuration of the pressure-volume curves was also the same when pressures were applied in descending or ascending order, or even when no regular sequence was followed.

In the observations described above capillary blood pressure was elevated by venous congestion and the rise in $P_{m v c}$ was associated with a reduction of "dynamic vascular volume." This might lead to the supposition that these two quantities were related inversely under all conditions. Preliminary studies have indicated that cooling of the forearm reduces both $P_{m v c}$ and "dynamic vascular volume." Conversely, exercising the forearm muscles raises $P_{\text {moc }}$ beyond the highest normal limits in most instances, while vascular volume is usually greater than normal. It appears therefore that under different conditions $P_{m v c}$ and "dynamic vascular volume" can vary independently.

In using this procedure to study the peripheral circulation under abnormal conditions it would seem advisable to use both Methods I and II together rather than either one separately. Preliminary observations in patients with hypertension and with reduced blood volume indicate that under abnormal conditions the pressure-volume curves obtained by these two methods differ more than they do in normal subjects. In these two conditions heightened arteriolar tone changes the position of the right limb of the pressure-volume curves, but this distortion is lessened even by mild reactive hyperemia.

Finally, this plethysmographic method of measuring the effect of external pressure on the vascular volume and the collective intravascular pressure in the minute vessels of the forearm has the weakness inherent in any "indirect method" of measurement because the criterion is an arbitrary one. The pressure-volume curves seem to be more reproducible than the purely visual criteria used in other indirect methods (3) and they have been shown to be modified characteristically when tested during venous congestion of known grade. The method is objective, includes large numbers of minute vessels, and avoids errors due to the proximity of the arteriovenous anastomoses. With the addition of graphic recording of volume changes, it is being used for studying the minute vessels in clinical conditions in a manner quite impossible with the direct micro-injection method.

\section{SUMMARY}

The pressure plethysmograph was used to determine the effect of graded external pressure on the vascular volume of the forearm, for the purpose of determining the usefulness of this procedure in estimating the blood pressure in the minute vessels collectively.

With external pressures ranging from 0 to 90 $\mathrm{mm}$. $\mathrm{Hg}$, pressure-volume curves were determined in 20 normal subjects (a) by suddenly arresting the circulation to the forearm and measuring decrease in volume, and (b) by releasing circulation suddenly after prior arrest and measuring increase in volume during the ensuing mild hyperemia. The term "dynamic vascular volume" was used to indicate that the volume of blood in actual movement was being measured under these conditions.

In the normal forearm "dynamic vascular volumes" were greatest when external pressure was between 15 and $35 \mathrm{~mm}$. $\mathrm{Hg}$, becoming less at external pressures above and below this range.

To record the relation between "dynamic vascular volume" and external pressure in the form of a single numerical value, an objective method of analyzing the pressure-volume curves was adopted. The single value thus obtained was termed $P_{m v c}$ and was defined as "that external pressure at which the vis a tergo of the circulation is able to keep open the greatest collective dynamic vascular volume."

$P_{m v c}$ determined in the forearms of 20 normal subjects with the forearm segment at heart level and at $34^{\circ} \mathrm{C}$. was 27,21 and $21 \mathrm{~mm}$. $\mathrm{Hg}$ by Methods I, II and III respectively. Reasons are given for regarding Methods I and II as the most 
useful. In the normal subject the results by all three methods had roughly the same order of magnitude as average capillary blood pressure when determined directly.

This similarity between $P_{m v c}$ and directly determined capillary blood pressure held also when the latter was reduced by elevating the forearm or increased by known venous congestion and by depressing the forearm below heart level.

With due precaution against assuming too quickly the quantitative validity of any indirect method of measuring intravascular pressure, it is suggested that the plethysmographic method may be useful in studying the volume of blood and the pressure in the minute vessels of the forearm in clinical conditions.

\section{PROTOCOL I}

Normal subject, J. E.; blood pressure $110 / 72 \mathrm{~mm}$. $\mathrm{Hg}$, December 12, 1940.

The plethysmograph-burette system was arranged as described. The plethysmograph was fitted to left forearm, small pneumatic cuffs were applied around wrist and upper arm, and water levels were adjusted to give atmospheric pressure. Temperature of the water in the bath was $34^{\circ} \mathrm{C}$., and of the room, $28^{\circ} \mathrm{C}$.

The pressure in the plethysmograph was elevated to $100 \mathrm{~mm}$. $\mathrm{Hg}$ three times to settle the rubber sleeve against the forearm.

\section{Time}

Minutes, Seconds

$0: 00$ (a) The wrist cuff was inflated to $300 \mathrm{~mm}$. $\mathrm{Hg}$ pressure. (b) The pressure applied to the water in the burette and the burette reservoir and thence to the forearm in the plethysmograph was $0.0 \mathrm{~mm}$. $\mathrm{Hg}$.

$0: 10$ The burette reservoir (Figure 1, J) was excluded by closing stopcock $\mathrm{Y}$.

2:00 The volume read in the burette was $20.2 \mathrm{cc}$. (column 3, below).

2:01 Circulation was arrested by inflating the arm cuff to $300 \mathrm{~mm}$. $\mathrm{Hg}$.

4:00 The volume read in burette was 26.8 cc. (column 4).

4:01 Circulation was restored by deflating the arm cuff.

4:10-4:15 The maximum (peak) volume during reactive hyperemia, read in the burette, was 13.1 cc. (column 5).

5:00 (a) The final volume read in burette was 17.5 cc. (column 6).

(b) The wrist cuff was deflated.

(c) Stopcock $Y$ to the burette reservoir was opened.

5:00-9:00 Rest period.

(9:00= time $0: 00$ for next determination.)

0:00 (a) The wrist cuff was inflated to $300 \mathrm{~mm}$. $\mathrm{Hg}$ pressure.

(b) Pressure applied to the water in the burette and thence to the forearm in the plethysmograph was $10 \mathrm{~mm}$. $\mathrm{Hg}$.

$0: 10$ The burette reservoir was excluded by closing stopcock Y.

2:00 The volume read in the burette was $22.2 \mathrm{cc}$ (column 3).

2:01 Circulation was arrested by inflating the arm cuff to $300 \mathrm{~mm}$. $\mathrm{Hg}$.

TABLE IV

Protocol I completed and summarized

\begin{tabular}{|c|c|c|c|c|c|c|c|}
\hline $\begin{array}{c}\text { Time deter- } \\
\text { mination } \\
\text { started }\end{array}$ & $\begin{array}{l}\text { Pressure applied } \\
\text { to surface of } \\
\text { forearm in ple- } \\
\text { thysmograph }\end{array}$ & $\begin{array}{c}\text { Burette reading } \\
\text { after } 2 \text { minutes } \\
\text { of external } \\
\text { pressure with } \\
\text { circulation } \\
\text { intact }\end{array}$ & $\begin{array}{l}\text { Burette reading } \\
\text { after } 2 \text { minutes } \\
\text { of ischemia and } \\
\text { continued ex- } \\
\text { ternal pressure }\end{array}$ & $\begin{array}{c}\text { Burette reading } \\
\text { at peak of reac- } \\
\text { tive hyperemia, } \\
\text { during con- } \\
\text { tinued external } \\
\text { pressure }\end{array}$ & $\begin{array}{c}\text { Final burette } \\
\text { reading at end } \\
\text { of } 5 \text { th minute } \\
\text { of external } \\
\text { pressure }\end{array}$ & $\begin{array}{c}\text { Decrease in } \\
\text { volume during } \\
\text { ischemia and ex- } \\
\text { ternal pressure } \\
\text { (column } 4 \text { minus } \\
\text { column 3) }\end{array}$ & $\begin{array}{l}\text { Increase in } \\
\text { volume during } \\
\text { reactive hy- } \\
\text { peremia and ex- } \\
\text { ternal pressure } \\
\text { (column 4 minus } \\
\text { column 5) }\end{array}$ \\
\hline 1 & 2 & 3 & 4 & 5 & 6 & 7 & 8 \\
\hline $\begin{array}{l}\text { minutes } \\
\text { seconds }\end{array}$ & $m m . H_{g}$ & $c c$. & $c c$. & $c c$. & $c c$. & $\begin{array}{l}\text { Method I } \\
\text { cc. }\end{array}$ & $\begin{array}{l}\text { Method II } \\
\text { cc. }\end{array}$ \\
\hline $\begin{array}{r}0: 00 \\
9: 00 \\
18: 00 \\
27: 00 \\
36: 00 \\
45: 00 \\
54: 00 \\
63: 00 \\
72: 00\end{array}$ & $\begin{array}{r}0 \\
10 \\
15 \\
20 \\
25 \\
30 \\
40 \\
50 \\
60\end{array}$ & $\begin{array}{l}20.2 \\
22.2 \\
22.0 \\
21.2 \\
21.6 \\
21.8 \\
21.1 \\
21.0 \\
23.2\end{array}$ & $\begin{array}{l}26.8 \\
32.6 \\
32.6 \\
32.0 \\
32.5 \\
31.8 \\
29.6 \\
27.1 \\
26.2\end{array}$ & $\begin{array}{l}13.1 \\
16.9 \\
17.3 \\
16.4 \\
17.5 \\
18.6 \\
16.8 \\
20.5 \\
23.6\end{array}$ & $\begin{array}{l}17.5 \\
21.5 \\
21.3 \\
20.5 \\
21.7 \\
21.0 \\
19.5 \\
20.5 \\
23.6\end{array}$ & $\begin{array}{r}6.6 \\
10.4 \\
10.6 \\
10.8 \\
10.9 \\
10.0 \\
8.5 \\
6.1 \\
3.0\end{array}$ & $\begin{array}{r}13.7 \\
15.7 \\
15.3 \\
15.6 \\
15.0 \\
13.2 \\
12.8 \\
6.6 \\
2.6\end{array}$ \\
\hline
\end{tabular}

Forearm measurements: circumferences, wrist $17.0 \mathrm{~cm}$. elbow $25.9 \mathrm{~cm}$.

length of segment in plethysmograph, $17.3 \mathrm{~cm}$. volume (calculated), $633 \mathrm{cc}$. 
4:00 The volume read in the burette was $32.6 \mathrm{cc}$. (column 4).

4:01 Circulation was restored by deflating the arm cuff.

4:10-4:15 The maximum (peak) volume read in burette was 16.9 cc. (column 5 ).

5:00 (a) The final volume read in burette was 21.5 cc. (column 6).

(b) The wrist cuff was deflated.

(c) Stopcock $Y$ to the burette reservoir was opened.

(d) Atmospheric pressure was restored in the burette-plethysmograph system.

5:00-9:00 Rest period. (18:00= time 0:00 for next determination) (et cetera, successively at pressures shown in table IV.

\section{BIBLIOGRAPHY}

1. Landis, E. M., Micro-injection studies of capillary blood pressure in human skin. Heart, 1930, 15, 209.

2. Fahr, G., and Ershler, I., Capillary pressure in right heart failure. Proc. Soc. Exper. Biol. and Med., 1938, 37, 701.

3. Eichna, L. W., and Bordley, J., III., Capillary blood pressure in man. Comparison of direct and indi- rect methods of measurement. J. Clin. Invest., 1939, 18, 695.

4. Landis, E. M., Capillary pressure and capillary permeability. Physiol. Rev., 1934, 14, 404.

5. Landis, E. M., and Gibbon, J. H., Jr., The effects of temperature and of tissue pressure on the movement of fluid through the human capillary wall. J. Clin. Invest., 1933, 12, 105.

6. Krogh, A., Landis, E. M., and Turner, A. H., The movement of fluid through the human capillary wall in relation to venous pressure and to the colloid osmotic pressure of the blood. J. Clin. Invest., 1932, 11, 63.

7. Lewis, T., The Blood Vessels of the Human Skin and Their Responses. Shaw and Sons, London, 1927.

8. Kendrew, A., The graphic registration of venous pressure in man, illustrated by some observations upon reactive hyperemia. Heart, 1926, 13, 101.

9. Carrier, E. B., and Rehberg, P. B., Capillary and venous pressure in man. Scandinav. Arch. $f$. Physiol., 1923, 44, 20.

10. Landis, E. M., Poiseuilles's law and the capillary circulation. Am. J. Physiol., 1933, 103, 432.

11. Landis, E. M., The capillary pressure in frog mesentery as determined by micro-injection methods. Am. J. Physiol., 1926, 75, 548. 